\title{
Labrador Sea Water: Pathways, CFC Inventory, and Formation Rates
}

\author{
M. Rhein, ${ }^{*}, * *$ J. Fischer, ${ }^{*}$ W. M. Smethie, ${ }^{+}$D. Smythe-Wright, ${ }^{\#}$ R. F. Weiss, ${ }^{@}$ C. Mertens,**** \\ D.-H. Min, $@,++$ U. Fleischmann, \& AND A. PutzKa \& \\ *Institut für Meereskunde Kiel, Kiel, Germany \\ ${ }^{+}$Lamont-Doherty Earth Observatory, Columbia University, Palisades, New York \\ \#Southampton Oceanography Centre, Southampton, United Kingdom \\ @ Scripps Institution of Oceanography, La Jolla, California

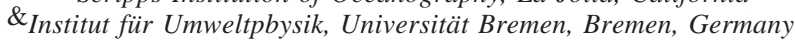

(Manuscript received 24 April 2000, in final form 7 November 2000)

\begin{abstract}
In 1997, a unique hydrographic and chlorofluorocarbon (CFC: component CFC-11) dataset was obtained in the subpolar North Atlantic. To estimate the synopticity of the 1997 data, the recent temporal evolution of the CFC and Labrador Sea Water (LSW) thickness fields are examined. In the western Atlantic north of $50^{\circ} \mathrm{N}$, the LSW thickness decreased considerably from 1994-97, while the mean CFC concentrations did not change much. South of $50^{\circ} \mathrm{N}$ and in the eastern Atlantic, the CFC concentration increased with little or no change in the LSW thickness. On shorter timescales, local anomalies due to the presence of eddies are observed, but for space scales larger than the eddies the dataset can be treated as being synoptic over the 1997 observation period.

The spreading of LSW in the subpolar North Atlantic is described in detail using gridded CFC and LSW thickness fields combined with Profiling Autonomous Lagrangian Circulation Explorer (PALACE) float trajectories. The gridded fields are also used to calculate the CFC-11 inventory in the LSW from $40^{\circ}$ to $65^{\circ} \mathrm{N}$, and from $10^{\circ}$ to $60^{\circ} \mathrm{W}$. In total, $2300 \pm 250$ tons of CFC-11 (equivalent to 16.6 million moles) were brought into the LSW by deep convection. In $1997,28 \%$ of the inventory was still found in the Labrador Sea west of $45^{\circ} \mathrm{W}$ and $31 \%$ of the inventory was located in the eastern Atlantic.

The CFC inventory in the LSW was used to estimate the lower limits of LSW formation rates. At a constant formation rate, a value of 4.4-5.6 Sv $\left(\mathrm{Sv} \equiv 10^{6} \mathrm{~m}^{3} \mathrm{~s}^{-1}\right)$ is obtained. If the denser modes of LSW are ventilated only in periods with intense convection, the minimum formation rate of LSW in 1988-94 is 8.1-10.8 Sv, and $1.8-2.4 \mathrm{~Sv}$ in $1995-97$.
\end{abstract}

\section{Introduction}

Labrador Sea Water (LSW) is a main component of North Atlantic Deep Water (NADW) and contributes to the cold branch of the global thermohaline circulation. LSW is formed in the central Labrador Sea by deep convection, which occasionally reaches well below $1500 \mathrm{~m}$. LSW is characterized by a minimum of salinity and potential vorticity and a maximum of chlorofluorocarbon (CFC) concentrations, and these signatures are found in the western and eastern subpolar North Atlantic. Three major pathways have been identified for LSW: spreading from the formation region to the northeast

\footnotetext{
** Current affiliation: Institut für Umweltphysik, Universität Bremen, Bremen, Germany.

++ Current affiliation: School of Oceanography, University of Washington, Seattle, Washington.
}

Corresponding author address: Dr. Monika Rhein, Universität Bremen, FB1, Institut für Umweltphysik, Abt. Ozeanographie, Kufsteiner Strasse, Geb. NW1, 28359 Bremen, Germany.

E-mail: mrhein@physik.uni-bremen.de into the Irminger Sea, spreading eastward into the eastern North Atlantic, and spreading southeastward with the deep western boundary current (Talley and McCartney 1982; Sy et al. 1997).

Intensity and depth of convection in the Labrador Sea varied significantly during the past 50 years (Lazier 1988). Intensive production of LSW occured in the mid1970s and again since the late 1980s. The modes of LSW formed in 1990-94 are the coldest and densest in this century. The intensity of convection is presumably linked to atmospheric variability, often presented as the NAO (North Atlantic Oscillation) index (e.g., Hurrell 1995). Intensive convective activity occurs during high NAO index periods, and weaker convection mostly during low NAO index periods (Dickson 1996). This simple picture might be obscured by variability of the freshwater fluxes and the variability in the stratification of the water column above the LSW. There is also some evidence that in some years deep convection might occur in the Irminger Sea, enhancing the area of LSW formation (R. Pickart 1999, personal communication). In climate models, the variability of the LSW pro- 


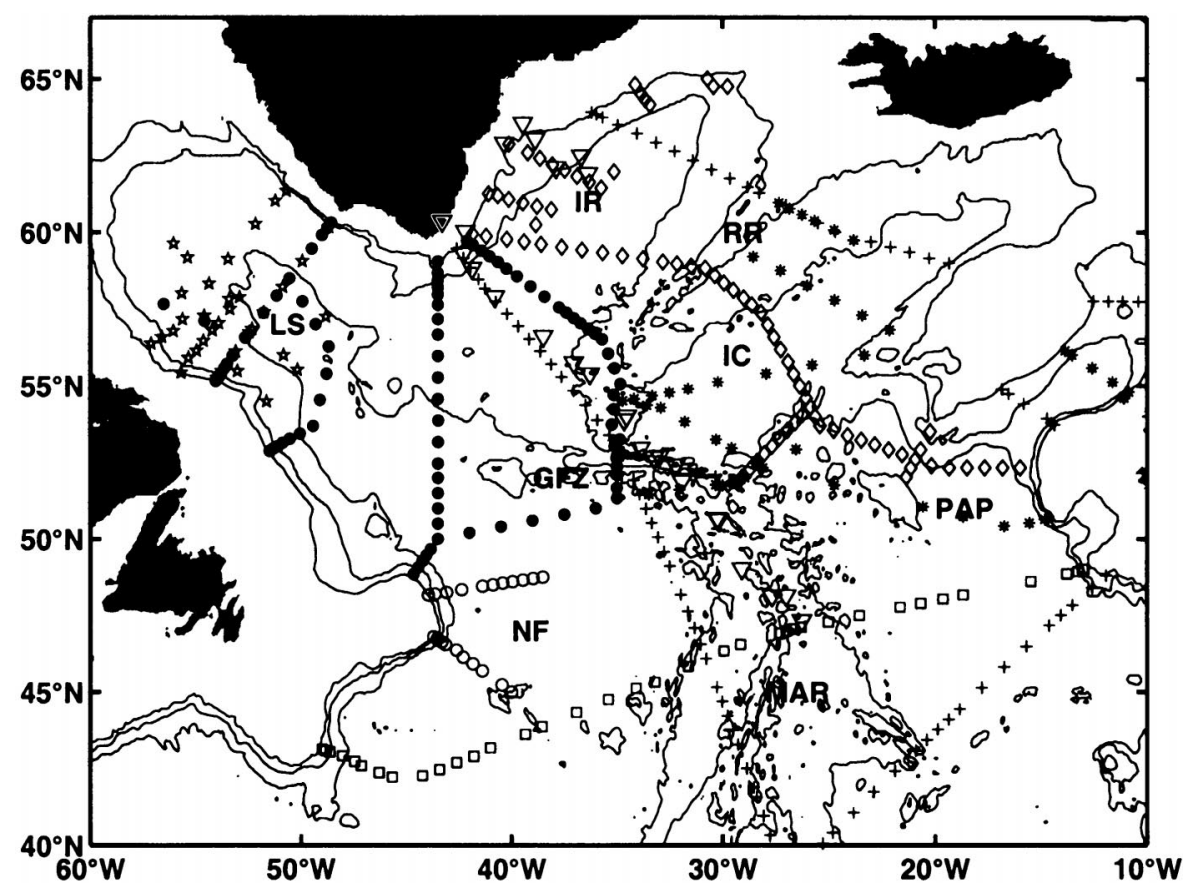

FIG. 1. CTD-CFC-11 stations from 1997 cruises: LS: Labrador Sea, NF: Newfoundland Basin, IR: Irminger Sea, IC: Iceland Basin, PAP: Porcupine Abyssal Plain; RT: Rockall Trough, GFZ: Charlie Gibbs Fracture Zone, RR: Reykjanes Ridge, MAR: Mid-Atlantic Ridge. Information and symbols of the cruises see Table 1 .

duction rates causes variability in transport of the thermohaline circulation and thus in the meridional oceanic heat transport (e.g., Delworth et al. 1993; Delworth and Greatbatch 2000). On the other hand, in studies with high-resolution ocean-only models (Böning et al. 1996) the link between LSW formation rate and strength of the thermohaline overturning breaks down when the deep-water masses below the LSW are adequately represented. Wood et al. (1999) ran an improved oceanic climate model and obtained a more realistic representation of the main ocean currents (including the representation of overflows) than previous coupled oceanatmosphere models. In this model, the meridional overturning in the Atlantic decreases by $20 \%-25 \%$ due to weakening of convection in the Labrador Sea when the greenhouse gases were quadrupled.

At present we still do not know whether in the real ocean the convection variability and thus the variability in LSW formation rate is linked to a variability in the meridional heat transport or variability in the transport of LSW out of the subpolar gyre. The knowledge of how much LSW is formed each year is crucial to address these issues. Mean LSW formation rates have been estimated from hydrographic data, from buoyancy fluxes, and from an a priori knowledge about the magnitude of the thermohaline circulation. The values range from 2 to $11 \mathrm{~Sv}\left(\mathrm{~Sv} \equiv 10^{6} \mathrm{~m}^{3} \mathrm{~s}^{-1}\right.$ : Worthington 1976; Clarke and Gascard 1983; McCartney and Talley 1984; McCartney 1992; Speer and Tziperman 1992). Assuming that the overturning of the North Atlantic is entirely surface forced and neglecting mixing in the ocean, Marsh (2000) calculated time series of the production rate of LSW using climatologies of surface heat and freshwater fluxes, and he obtained a mean of $3.4 \mathrm{~Sv}$ for the 1980-97 time period, with a maximum value of 10 $\mathrm{Sv}$ in 1990 during the high NAO index period from 1988-94.

Smethie and Fine (2001) made the first effort to estimate rates of North Atlantic Deep Water formation from CFC data, collected between 1986 and 1992. After normalizing the observations to a common date, the CFC inventories of the various deep water masses were calculated. For LSW, a mean formation rate of $7.4 \mathrm{~Sv}$ was estimated for the 1970-90 time period. This estimate consisted of a formation rate that varied from 1.3 Sv to $12.5 \mathrm{~Sv}$ and was scaled to the observed thickness of LSW with greatest thickness and highest rates occuring during the mid 1970s and the late 1980s. Unfortunately, not enough CFC data exist to calculate the inventory for each year, making it necessary to assume a correlation with a feature that is available on a yearly timescale, such as the LSW thickness.

Here we combine hydrographic and CFC datasets obtained in the subpolar North Atlantic in 1997 (Fig. 1, Table 1), with Profiling Autonomous Lagrangian Circulation Explorer (PALACE) float trajectories. First we present the general CFC distribution in the water column and discuss the synopticity of the thickness and CFC fields. A topography-following interpolation scheme is applied to obtain a gridded dataset, which is used to 
TABLE 1. (a) 1997 cruises with CFC measurements. To enhance the dataset in the DWBC, two CFC sections off Newfoundland from 1996 and one section in the southern Labrador Sea from 1998 were added. The symbols refer to Fig. 1. (b) CFC sections used for the study of the temporal evolution. PI: principal investigator. LDEO: Lamont-Doherty Earth Observatory, Palisades, New York; IFMK: Institut für Meereskunde Kiel, Germany; IUPB: Institut für Umweltphysik, Universität Bremen, Germany; SIO: Scripps Institution of Oceanography, La Jolla, California, SOC: Southampton Oceanography Centre, Southampton, United Kingdom.

\begin{tabular}{|c|c|c|c|c|}
\hline Cruise & Symbol in Fig. 1 & Date & PI CFCs & Institution \\
\hline \multicolumn{5}{|c|}{ (a) 1997} \\
\hline Knorr 147 & Pentagram & 7 Feb-12 Mar 1997 & Smethie & LDEO \\
\hline Meteor 39/2 & Star & 5 May-7 Jun 1997 & Rhein & IFMK \\
\hline Knorr 151/2 & Cross & 30 May-2 Jul 1997 & Weiss & SIO \\
\hline Meteor 39/3 & Square & 13 Jun-30 Jun 1997 & Roether & IUPB \\
\hline Meteor 39/4 & Dark dot & 7 Jul-8 Aug 1997 & Rhein & IFMK \\
\hline Discovery 230 & Triangles & 7 Aug-17 Sep 1997 & Smythe-Wright & SOC \\
\hline Meteor 39/5 & Diamonds & 14 Aug-14 Sep 1997 & Rhein & IFMK \\
\hline Valdivia 161 & Circle & 19 Jul-16 Aug 1996 & Rhein & IFMK \\
\hline Valdivia 172 & Circle & 4 Jul-8 Aug 1998 & Rhein & IFMK \\
\hline \multicolumn{5}{|c|}{ (b) CFC sections } \\
\hline Meteor 18/2 & - & 2 Sep-26 Sep 1991 & Roether & IUPB \\
\hline Meteor 30/2 & - & 12 Oct-10 Nov 1994 & Roether & IUPB \\
\hline Meteor 30/3 & - & 15 Nov-12 Dec 1994 & Rhein & IFMK \\
\hline
\end{tabular}

discuss the spreading paths of LSW, to calculate the CFC inventory, and to estimate lower limits of LSW formation rates from 1988-97.

\section{Dataset and methods}

\section{a. CFC analysis}

Five different scientific groups sampled and analyzed the CFC-11 distribution in 1997 (Table 1). All water samples were analyzed on board with a gas chromatographic technique first described by Bullister and Weiss (1988). The precision of each dataset was checked by analyzing duplicates for $10 \%-15 \%$ of the samples and was found to be of the order of $\pm 1 \%$. Absolute calibration was done with standard gases calibrated against primary standards provided by R. F. Weiss, Scripps Institution of Oceanography, and D. W. R. Wallace, Institut für Meereskunde Kiel. The concentrations are reported on the SIO93 scale (Cunnold et al. 1994). The accuracies of the gas standards for CFC-11 range from $1 \%$ to $3 \%$.

We choose the $\sigma_{\Theta}=27.74$ and 27.80 density surfaces to bound the LSW. The isopycnals correspond to $\sigma_{1.5}=$ $34.60-34.63$ and $34.695-34.705$, respectively. These isopycnals are suitable to bound the LSW for the entire subpolar North Atlantic. The $\sigma_{\Theta}=27.80$ separates the LSW from the denser overflow waters, and the isopycnal is located between the salinity extrema of LSW and the overflow water. The $\sigma_{\Theta}=27.74$ separates the LSW from the lighter water masses, which are more saline than LSW.

The "classical" LSW (cLSW), from Smethie and Fine (2000), was bounded by $\sigma_{1.5}=34.62$ and 34.69. These boundaries could not be taken for the 1997 dataset because the intense convection that occurred in the early 1990s created LSW with densities greater than $\sigma_{1.5}=$ 34.69. In 1996-97, the $\sigma_{1.5}=34.69$ is located in the salinity minimum of LSW, which is the characteristic core layer of LSW throughout the entire subpolar North Atlantic (Talley and McCartney 1982; Sy et al. 1997). In order to calculate the formation rates of two LSW modes separately, the LSW is split into two density classes, the sLSW (shallow LSW) bounded by the isopycnals $\sigma_{\Theta}=27.74-27.77$, and the dLSW (deep LSW), bounded by $\sigma_{\Theta}=27.77-27.80$. These should not be confused with the upper LSW (Pickart 1992), which is less dense than the LSW modes discussed here. The dLSW encloses the salinity minimum zone (about $\sigma_{\Theta}=27.78$ ) found everywhere in the subpolar North Atlantic, and sLSW contains the lighter modes of LSW. These lighter modes are renewed more frequently, and the ventilation of the dLSW by deep convection occured most likely in high NAO index periods (McCartney and Talley 1984; Lazier 1988; Dickson et al. 1996).

In total, 2410 individual CFC-11 measurements on 465 stations have been obtained in the density range of LSW. On average, five measurements per profile are available for the calculation of the mean CFC-11 concentration of LSW, such that the vertical resolution is sufficient to calculate the mean CFC-11 concentration on each profile for sLSW and dLSW. On 59 profiles only one or two CFC-11 samples in the LSW were available; 21 of these profiles were located at the continental shelf, where the water depth was too shallow to cover the whole density range of LSW. The remaining low-resolution profiles are found near the CGFZ (Charlie-Gibbs Fracture Zone) and above the Reykjanes Ridge. The LSW layer above the ridge is very thin $(200 \mathrm{~m})$, so that the resolution there is sufficient, and the CGFZ profiles are surrounded by profiles with high vertical resolution. A more serious problem in calculating the mean CFC-11 concentrations for LSW might be the six low-resolution profiles clustered at $43^{\circ} \mathrm{N}, 47^{\circ} \mathrm{W}$ where the mean CFC values are determined by only one 


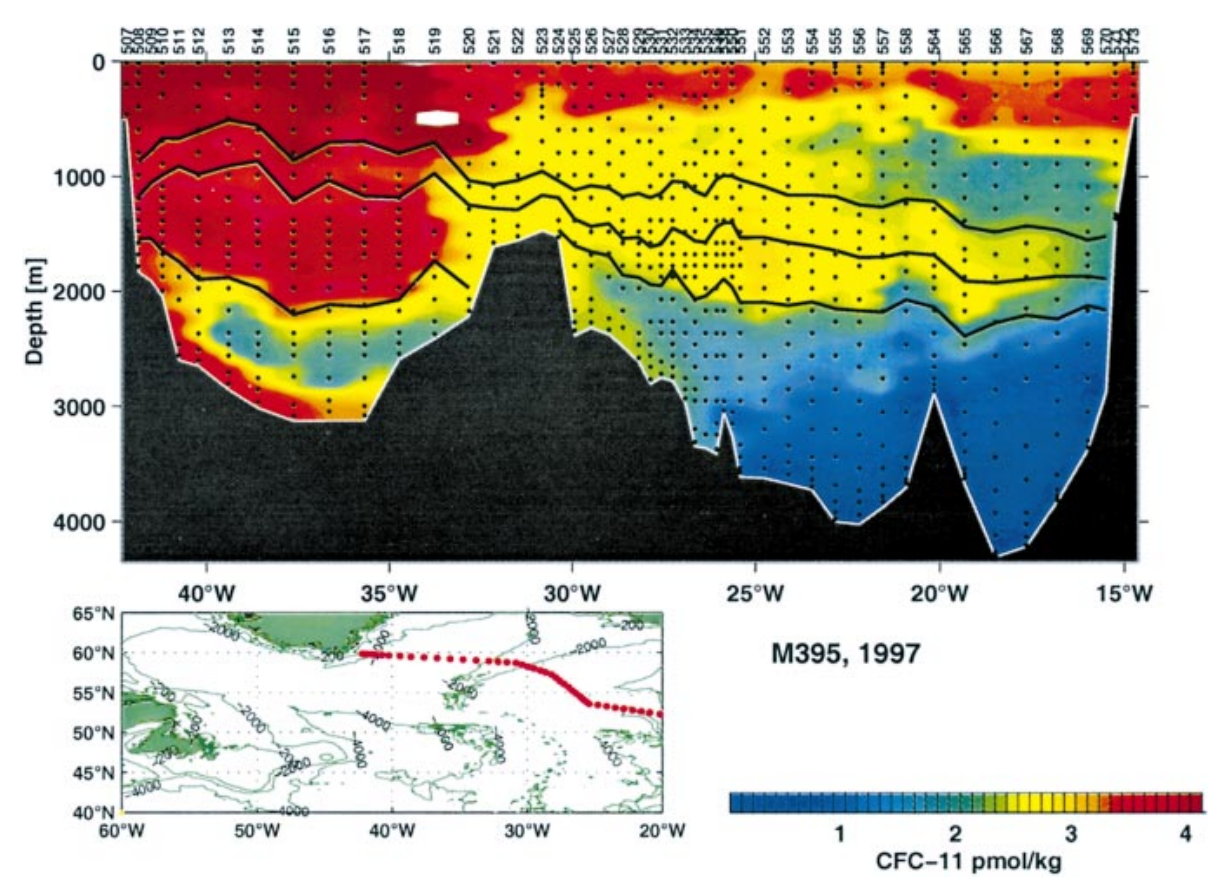

FIG. 2. CFC-11 (pmol kg-1) distribution along WOCE section A1E, Aug-Sep 1997. The isopycnals $\sigma_{\Theta}=27.74,27.77$, and 27.80 are included (black lines). The sLSW is bound by the 27.74 and 27.77 isopycnals, the dLSW by $\sigma_{\Theta}=27.77$ and 27.80 . The black dots show the location of the CFC measurements. The location of the section is shown in the inset map.

or two samples. For all profiles, the mean CFC-11 concentration of LSW is calculated by weighting the CFC values with the respective vertical distance they represent.

The tracer measurements in the subpolar North Atlantic in 1997 were carried out within an 8-month period. To provide a more complete dataset at the western boundary, two sections taken in August 1996 and one section in the southern Labrador Sea taken in August 1998 were added.

\section{b. Intercomparison}

We checked the consistency of the CFC-11 datasets by comparing CFC concentrations west of $32.5^{\circ} \mathrm{W}$ corresponding to densities between $\sigma_{\Theta}=27.77$ and $\sigma_{\Theta}=$ 27.79 and falling in the same narrow temperature $( \pm 0.003)$ and salinity $( \pm 0.003)$ range. Convection did not reach this density layer in 1996, 1997, and 1998, and according to Sy et al. (1997) LSW from the Labrador Sea spreads into the western basin on timescales of 1 yr. The $\sigma_{\Theta}=27.79$ was chosen as a lower limit to minimize the effect of mixing with denser water masses $\left(\sigma_{\Theta}>27.80\right)$, which have regionally different CFC concentrations.

For individual cruises the mean standard deviation of the CFC-11 values within the aforementioned $\Theta$ and $S$ space is $2.5 \%-3 \%$, composed of the measurement precision (about 1\%) and regional differences. For the whole dataset the mean standard deviation increases to
$4.5 \%$; that is, the cruises are consistent on a $4 \%$ level. The major part of the intercruise differences are from the error in the accuracy of the CFC gas calibration standards $(1 \%-3 \%)$.

\section{Tracer distribution and temporal evolution of the tracer signal in the subpolar North Atlantic}

\section{a. CFC-11 distribution and the deep water masses}

To give an overview on the vertical CFC field in the subpolar North Atlantic, the CFC-11 distribution along WOCE line A1E from 1997 is presented (Fig. 2). In the Irminger Sea, dLSW exhibits higher CFC levels than sLSW. Below the LSW, the Iceland-Scotland overflow water (ISOW) is visible in the Irminger Sea as a CFC minimum reaching from the Reykjanes Ridge to $40^{\circ} \mathrm{W}$. The CFC maximum near the bottom west of $35^{\circ} \mathrm{W}$ represents the Denmark Strait overflow water (DSOW).

In the eastern Atlantic, the CFC levels are generally lower than in the western basins. In the mixed layer the decrease is caused by higher temperatures, allowing less CFCs to be dissolved. In middepth the CFC-11 maximum of the LSW is still a prominent signal, and the vertical CFC gradient between sLSW and dLSW is small. The LSW layer is very thin above and at the eastern flank of the Reykjanes Ridge $(500 \mathrm{~m})$, but thickens again in the Iceland Basin. A CFC maximum is found near $25^{\circ} \mathrm{W}$ at the eastern side of the Iceland Basin. The maximum is a permanent feature, which was al- 
ready observed on two previous cruises in 1991 and 1994 (Sy et al. 1997; Smethie et al. 2000). At the eastern flank of the Reykjanes Ridge high CFC concentrations are found near the bottom, indicating the ISOW in the Iceland Basin. ISOW crosses into the western Atlantic through the CGFZ and, as mentioned before, forms the intermediate CFC minimum because in the western Atlantic ISOW encounters the CFC-richer deep water components LSW and DSOW. The lower CFC values of ISOW on the western flank of the Reykjanes Ridge compared to the ISOW on the eastern slope cannot be caused by mixing with LSW and DSOW, which are both richer in CFCs. The comparably weak CFC signal of ISOW at the western flank indicates that the main path of ISOW in the western Atlantic is not into the Irminger Sea as is commonly believed. Instead, ISOW spreads mainly into the Labrador Sea. A fraction of the ISOW remains in the Northeast Atlantic, flowing southward along the Mid-Atlantic Ridge (Smethie et al. 2000; Fleischmann et al. 2002). The very low CFC concentrations below the LSW in the eastern Atlantic characterize the Eastern Atlantic Bottom Water that has some Antarctic Bottom Water contributions (McCartney 1992).

\section{b. Temporal evolution of the CFC-11 and thickness distribution of $L S W$}

In order to get an idea whether we can treat the CFC concentrations in 1997 as being synoptic, we present here the temporal evolution of the CFC signal in the LSW since 1991. The CFC-11 concentrations in the sLSW west of the Reykjanes Ridge increased only slightly since 1991 (Fig. 3a), but in the eastern Atlantic the CFC level rose considerably between 1991 and 1994 and from 1994 to 1997. For dLSW the most dramatic change occured in the Irminger Sea between 1991 and 1994 caused by the invasion of newly ventilated CFCrich LSW. (Fig. 3b). Since 1994 the CFC concentrations remained almost constant because the density layers of dLSW were not ventilated by deep convection. In contrast, owing to the longer travel time, formerly ventilated dLSW continued to invade the eastern Atlantic and the CFC levels increased steadily since 1991. Between 1991 and 1994 the increase was observed mainly west of $22^{\circ} \mathrm{W}$ (Iceland Basin), and in 1994-97 the increase was most pronounced in the eastern part of the section. This indicates the eastward propagation of LSW modes with high $\mathrm{CFC}$ concentrations.

The CFC-11 increase in the eastern Atlantic is about $0.1 \mathrm{pmol} \mathrm{kg}^{-1} \mathrm{yr}^{-1}$ for the sLSW (period 1994-97). For the dLSW, the rates increase from $0.05 \mathrm{pmol} \mathrm{kg}^{-1} \mathrm{yr}^{-1}$ near the Reykjanes Ridge to $0.3 \mathrm{pmol} \mathrm{kg}{ }^{-1} \mathrm{yr}^{-1}$ at $24^{\circ} \mathrm{W}$ and remain constant farther east. The regionally different rates of temporal CFC change from 1991 to 1997 show that it would not be appropriate to normalize the CFC data from these time periods to a common year by multiplying them with a constant factor as it was pos- sible for the 1986-90 time period by Smethie and Fine (2001).

The LSW thickness did not change much in the eastern Atlantic from 1991 to 1997 (Fig. 3c). In the Irminger Sea the LSW was thicker in 1994 than in 1997 and in 1991. The thickness change is caused by the downward shift of the $\sigma_{\Theta}=27.74$ isopycnal. From 1994 to 1997 the LSW thickness decreased at a rate of $150-200 \mathrm{~m}$ $\mathrm{yr}^{-1}$. In the Labrador Sea the LSW thickness decreased from July 1996 to June 1997 by about 150-200 m, and the CFC-11 concentrations in the LSW decreased by $0.1-0.2 \mathrm{pmol} \mathrm{kg}^{-1}$ (differences between the observations for the cruises R/V Valdivia 161 in 1996 and M394 in 1997). Between $42^{\circ}$ and $48^{\circ} \mathrm{W}$ along the WOCE A2 section, the CFC-11 increase from 1994 to 1997 was $0-0.1 \mathrm{pmol} \mathrm{kg}^{-1} \mathrm{yr}^{-1}$ for the western basin, and 0.2 0.3 pmol kg-1 $\mathrm{yr}^{-1}$ for the eastern basin. In general, in 1994-97, the LSW variability in the western basin north of $50^{\circ} \mathrm{N}$ is dominated by a thickness decrease, and in the region south of $50^{\circ} \mathrm{N}$ and the eastern basins by an increase in the CFC-11 concentrations. The decrease of LSW thickness of about $150 \mathrm{~m} \mathrm{yr}^{-1}$ in the western basins north of $50^{\circ} \mathrm{N}$ also means that the volume of LSW in the subpolar North Atlantic decreased since 1994. If one attributes the decrease solely to southward export and neglects mixing, the volume decrease would correspond to a southward LSW transport of $10 \mathrm{~Sv}$.

\section{Inferring gridded CFC-11 and thickness fields of the LSW}

Having presented the CFC distribution and its temporal evolution, we now describe the methods applied to obtain gridded fields of CFC-11 and LSW thickness.

Both the CFC-11 distributions of LSW (Fig. 4) and the trajectories of the PALACE floats (Fig. 5) seem to follow the large-scale contours of the planetary potential vorticity $f / H$ ( $f$ : Coriolis parameter, $H$ : water depth, (Fig. 5). Thus, a topography-following mapping scheme was adapted from Davis (1998) to interpolate the horizontal CFC-11 and thickness distribution on a regular spatial grid $\left(0.25^{\circ}\right.$ latitude by $0.5^{\circ}$ longitude) from $40^{\circ}$ to $65^{\circ} \mathrm{N}$ and from $60^{\circ}$ to $10^{\circ} \mathrm{W}$. The preferable method to perform such an interpolation would be objective mapping. Doing this for the CFC distribution needs an a priori knowledge of the data covariance that is not known. What is known from hydrographic and tracer observations, from float trajectories, and current measurements are the horizontal scales of these fields at key locations of the subpolar North Atlantic. Boundary current regimes are approximately $100 \mathrm{~km}$ wide with strong gradients along their offshore edges. There is a broad eddy field associated with the North Atlantic Current crossing the central basins (horizontal scales about 300 $\mathrm{km})$. And there are some indications of the size of the convective area in the Labrador Sea (diameter about $300-500 \mathrm{~km}$ ). Bearing these scales in mind, we constructed an interpolation scheme that takes into account 

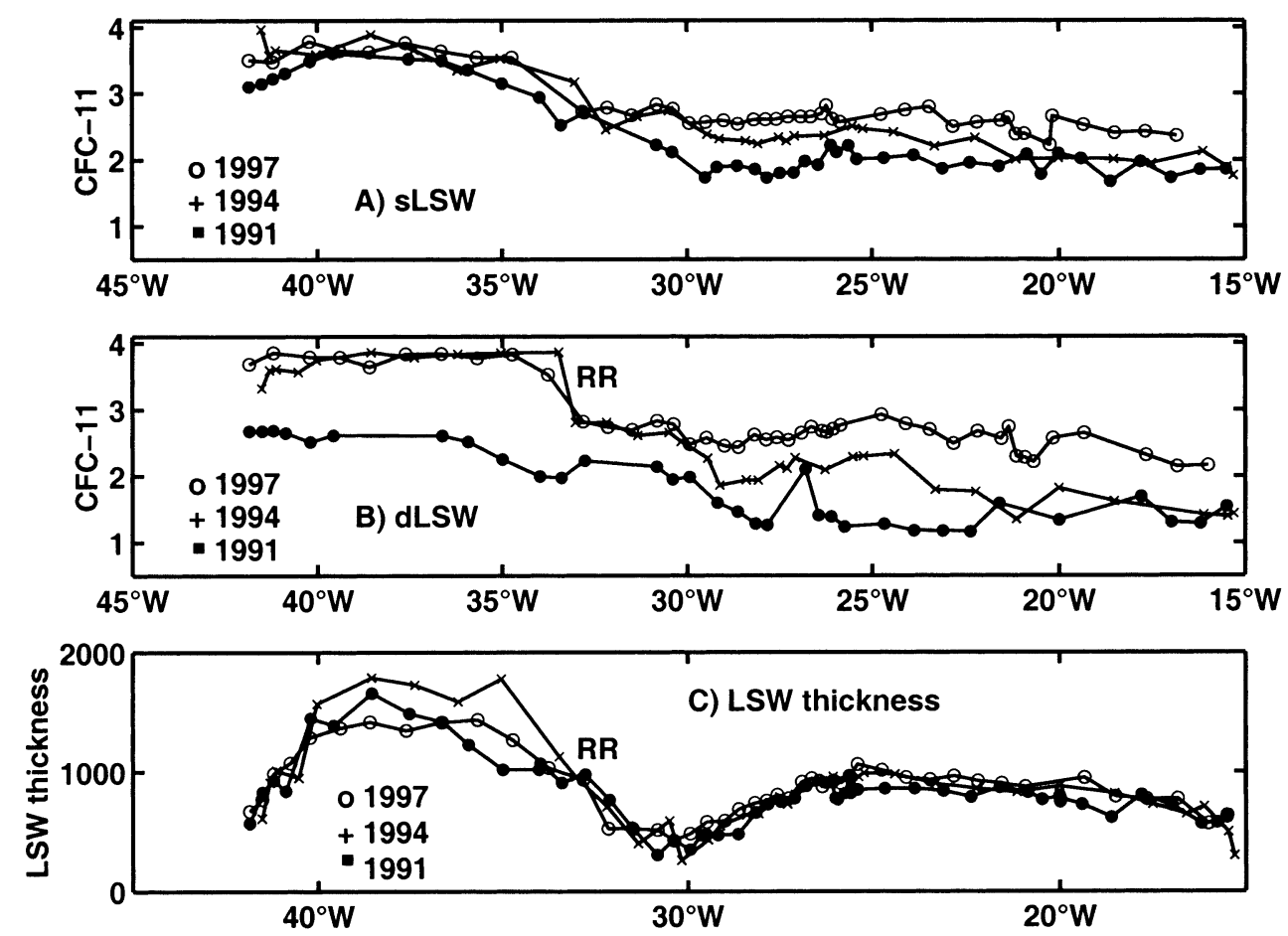

FIG. 3. Mean CFC-11 (pmol kg-1) concentration along WOCE section A1E, for (a) sLSW $\left(\sigma_{\Theta}=27.74\right.$ $27.77)$ and (b) dLSW $\left(\sigma_{\Theta}=27.77-27.80\right)$; (c) LSW thickness $\left(\sigma_{\Theta}=27.74-27.80\right)$. At the stations above the Reykjanes Ridge (RR) the $\sigma_{\Theta}=27.80$ isopycnal does not exist. Here, the bottom was taken as the lower bound. The data are from R/V Meteor cruises M18-2 and M39-5 (see Table 1).

the horizontal scales and the role of topography near the boundaries. "Gaussian" weights were determined as

$$
W=e^{-R^{2}}
$$

with the "generalized" distance $\mathrm{R}$ defined as

$$
R^{2}=\frac{|\mathbf{a}-\mathbf{b}|^{2}}{\Lambda}+\frac{1}{\Phi} \frac{|\mathrm{PV}(\mathbf{a})-\mathrm{PV}(\mathbf{b})|^{2}}{\mathrm{PV}^{2}(\mathbf{a})+\mathrm{PV}^{2}(\mathbf{b})}
$$

In Eq. (2) $\mathbf{a}$ are the positions of grid points and $\mathbf{b}$ those of the measurements, such that the first term of the right-hand side of (2) is the squared distance between grid and data points divided by a horizontal scale factor $(\Lambda)$. The second term takes account of the differences in barotropic potential vorticity:

$$
\mathrm{PV}=\frac{f}{H},
$$

with $f$ the planetary vorticity and $H$ the water depth, which is scaled by $\Phi$. The scaling parameters were chosen $\left(\Lambda=0.5 \times 10^{-4}, \Phi=100\right)$ such that the first term in Eq. (2) has a half-width of $150 \mathrm{~km}(10 \%$ weight at $220 \mathrm{~km}$ ) and is equivalent to a depth difference of 150 $\mathrm{m}$ in the second term. The interpolation method preserves the observed strong CFC gradients at the boundaries. Figure 6 gives examples of the weighting functions for various grid points. In the interior of the basins the weighting function is isotropic, and close to topo- graphic slopes the weighting function follows the topography.

To illustrate the effect of the mapping procedure on the mean distributions and the regional variability we interpolated the data to their original positions with the same interpolation scheme. The interpolated data were virtually unchanged compared to the observations; that is, differences of the fields were negligible on average and distributed randomly in space. In the frequency distribution plot of the differences between interpolated and measured CFC-11 values and LSW thickness, the differences are symmetrically distributed around zero and the rms of the differences is $7 \%$ for CFC- 11 and $12 \%$ for layer thickness relative to the mean $\mathrm{CFC}$ and thickness value, respectively (Fig. 7).

The calculated CFC-11 and LSW thickness fields are presented in Figs. 8 and 9. To assess the uncertainty in the two fields, we performed a variational statistical method known as jackknifing. The CFC-11 and the LSW thickness fields were calculated by randomly choosing $50 \%$ of the data, and the rms at each grid point was calculated from 100 realizations of the CFC-11 and the thickness field, respectively. The resulting rms scatter at each grid point is a measure of the combined effect of measurement errors, small-scale nonsynopticity, and low data coverage. The distributions of the rms values of the CFC-11 and the thickness field of LSW on the individual grid points are presented in Fig. 10. 
LSW, 1997, CFC-11, sigth $=27.74-27.80$

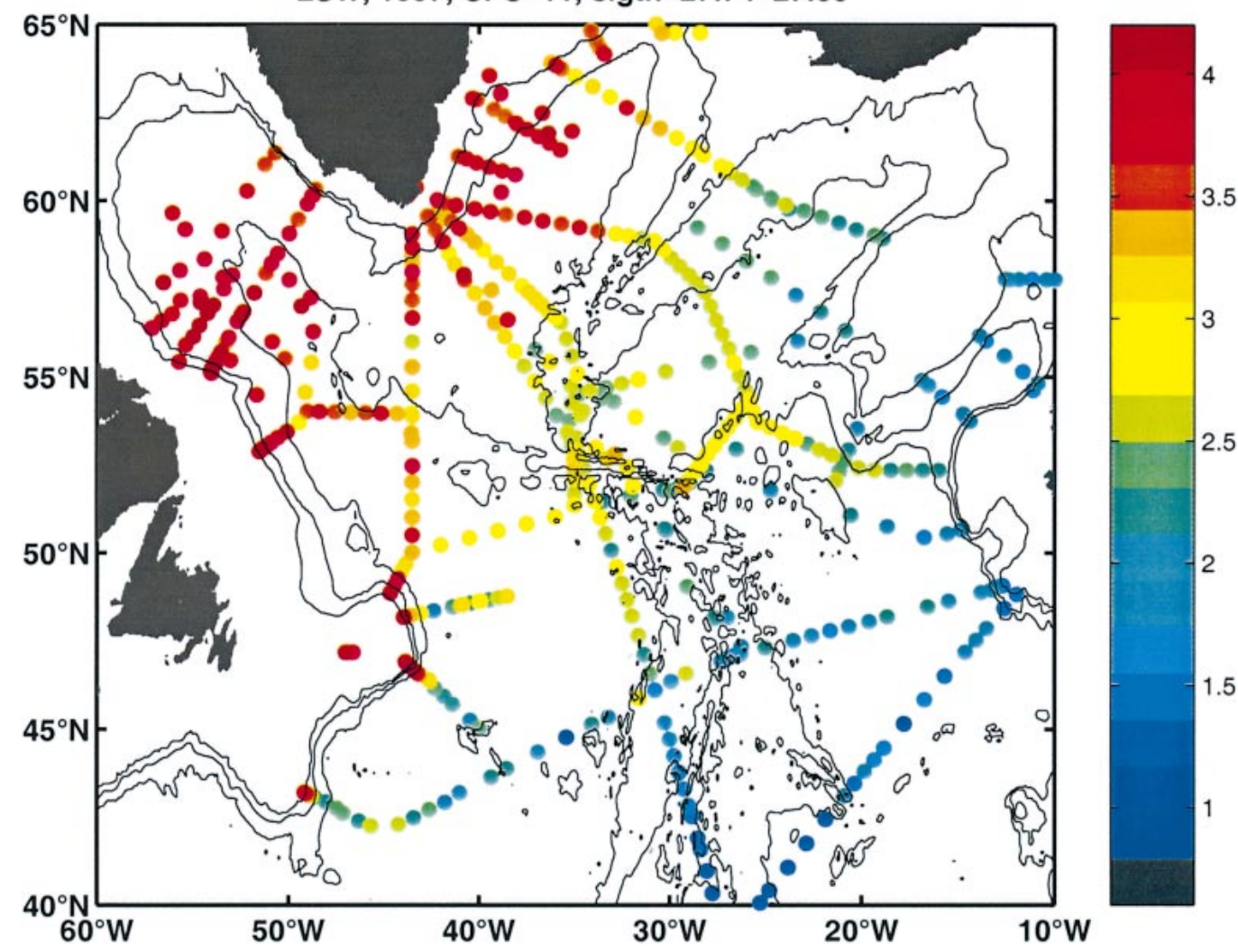

FIG. 4. Mean CFC-11 concentration $\left(\mathrm{pmol} \mathrm{kg}{ }^{-1}\right)$ of $\operatorname{LSW}\left(\sigma_{\Theta}=27.74-27.80\right)$ at individual stations.

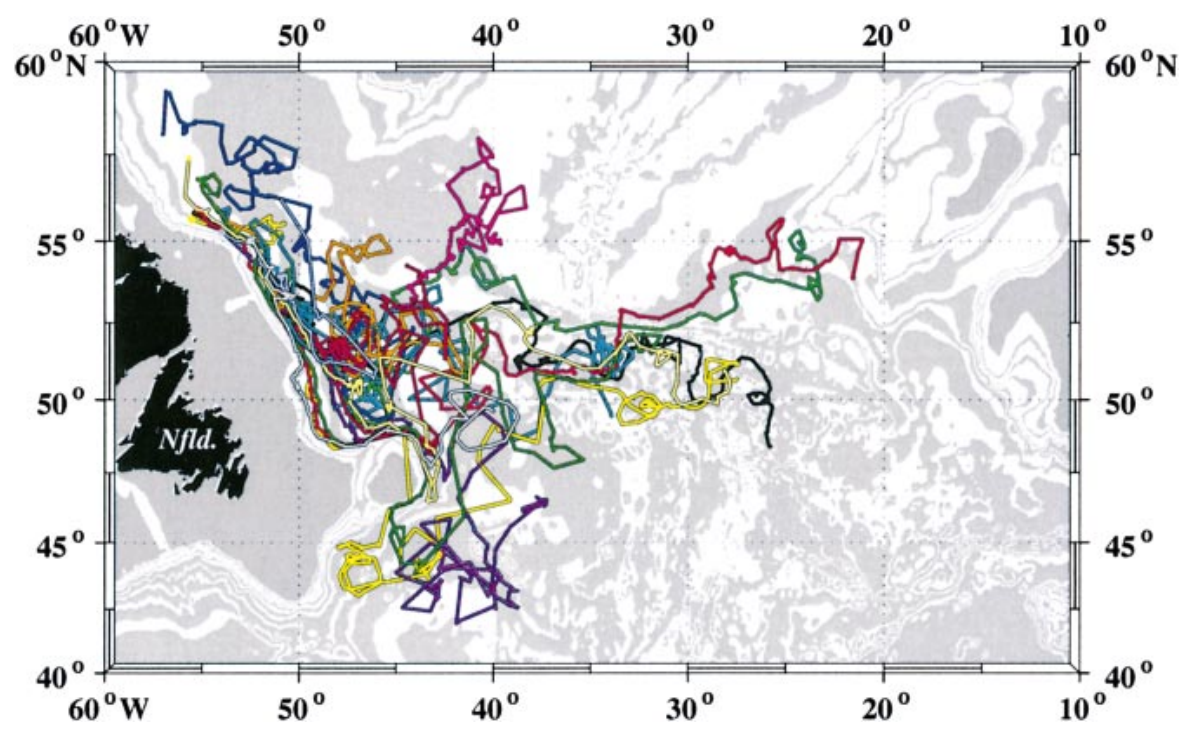

FIG. 5. $f / H$ contours $\left(1 \times 10^{-6} \mathrm{~m}^{-1} \mathrm{~s}^{-1}\right)$ in the subpolar North Atlantic. $f$ : Coriolis parameter, $H$ : water depth. The TerrainBase, Global 5-Minute Ocean Depth and Land Elevation (TBASE) topographic dataset, developed from multiple data sources and compiled by the National Geophysical Data Center, Boulder, CO, was used to calculate the contours. Also included are the trajectories of PALACE floats at 1500-m depth, 1997-99. The floats were released in the Labrador Sea close to the continental slope in the deep boundary current between $53^{\circ}$ and $55^{\circ} \mathrm{N}$. PALACE float tracks are taken from Fischer and Schott (2002, their Fig. 1). 


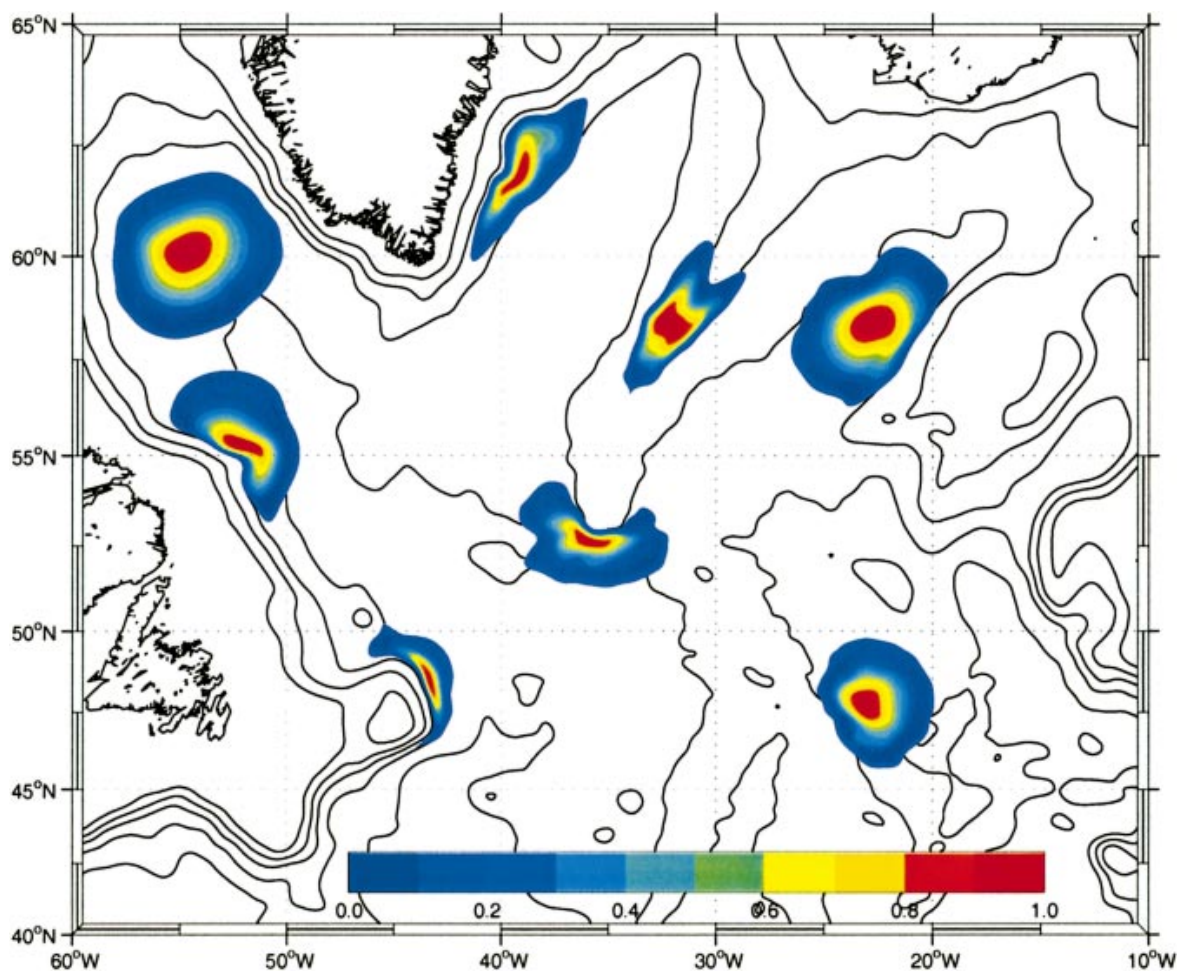

FIG. 6. Examples for the weighting function on individual grid points. Weights smaller than $1 \%$ were ignored. A smoothed TBASE topographic dataset was used.

For the CFC field, rms values exceeding $10 \%$ (red color) are found off Newfoundland near the continental slope and on the western side of the Mid-Atlantic Ridge between $42^{\circ}$ and $48^{\circ} \mathrm{N}$. The high rms is caused by poor

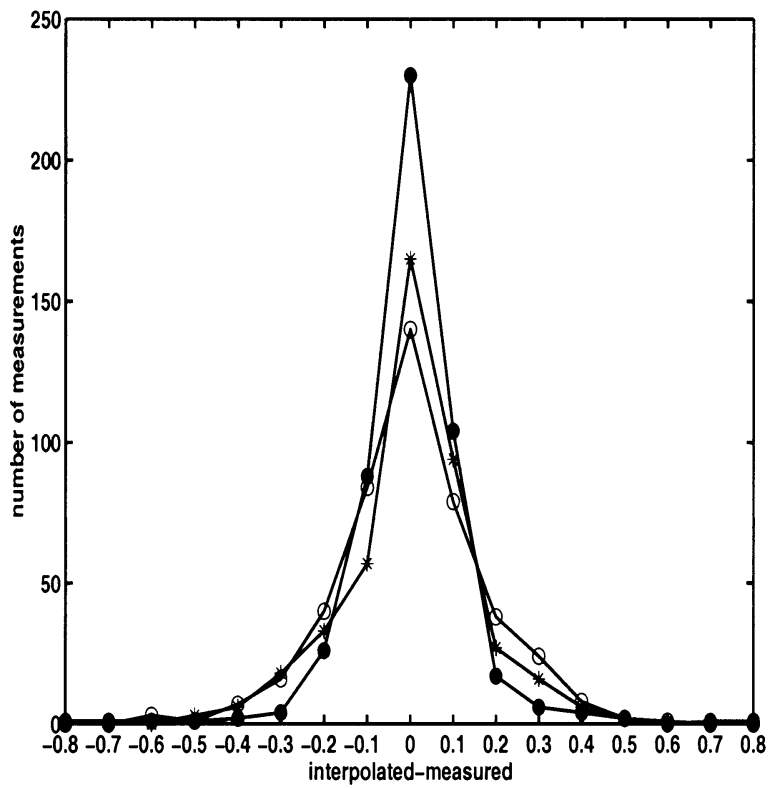

sampling and/or by large CFC gradients in these regions. The rms in the thickness field is high in regions with large thickness gradients along the continental slopes north of $50^{\circ} \mathrm{N}$, along the Reykjanes Ridge, and in the

FIG. 7. Frequency distribution plot of the difference between interpolated and measured CFC-11 concentrations (left) and interpolated and measured thicknesses (right) for $\sigma_{\Theta}=27.74-27.80$ (black dots), 27.77-27.80 (open circles), and 27.74-27.77 (stars). The locations where only one station was within range (i.e., the measured and the calculated values are identical) were omitted from these calculations. 


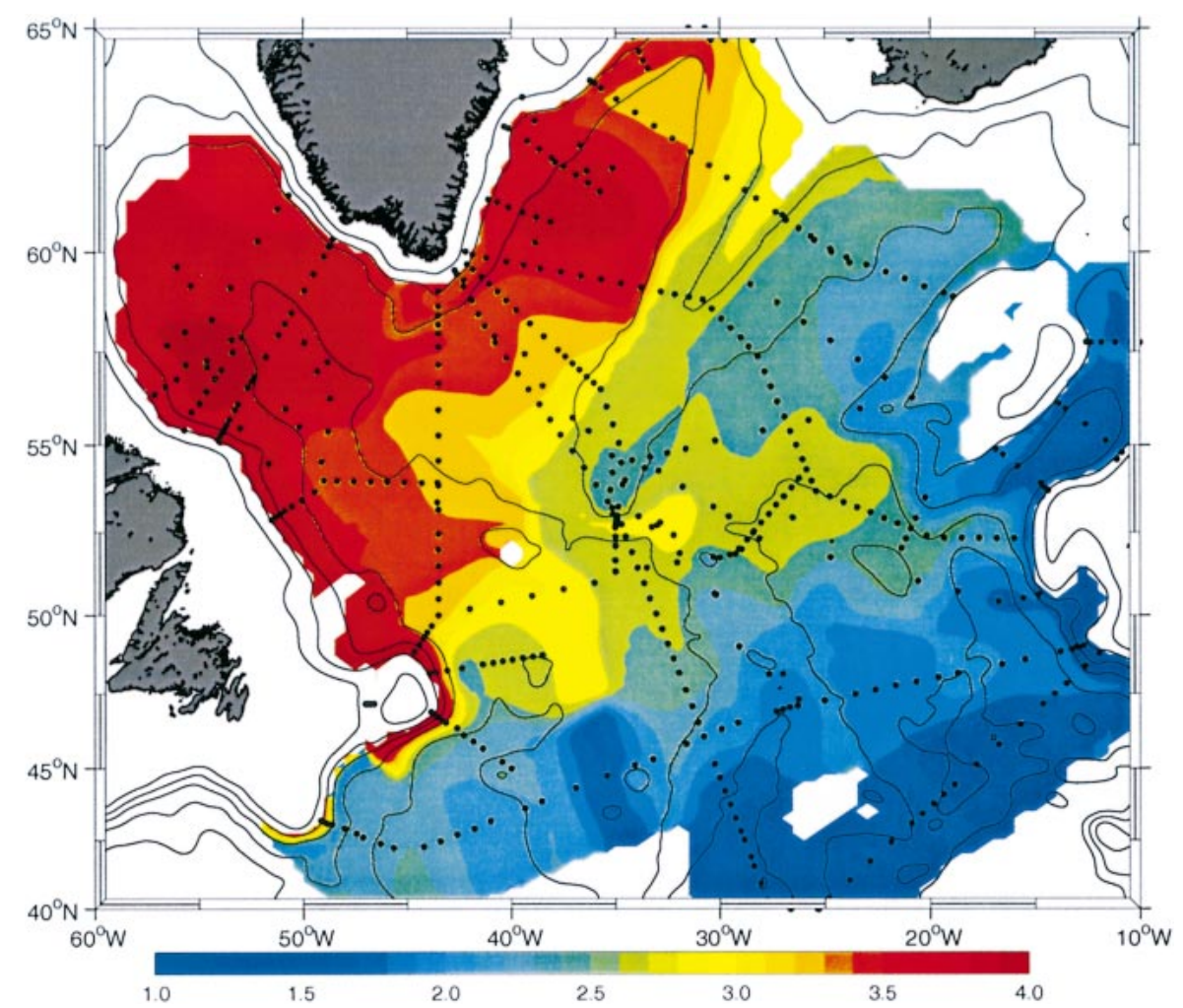

FIG. 8. CFC ( $\mathrm{pmol} \mathrm{kg}^{-1}$ ) distribution of LSW interpolated with the procedure published by Davis (1998) from the data shown in Fig. 4. A smoothed TBASE topographic dataset was used.

eastern basin at $20^{\circ} \mathrm{W}$ south of $45^{\circ} \mathrm{N}$. Both presentations show regions with low data coverage associated with low error estimates. This somewhat counterintuitive result is caused by the small horizontal CFC and thickness gradients observed in these regions; that is, all randomly chosen observations lead to similar interpolation results in the aforementioned regions.

\section{LSW pathways in the subpolar North Atlantic}

Various distinct paths for the spreading of LSW can be deduced from Fig. 8. The highest CFC concentrations and the largest thickness (Fig. 9) are found in the central Labrador and Irminger Seas. High CFC values are also found along the western margin of the Newfoundland Basin. These features reflect the LSW formation in the central Labrador Sea and its export in the southeastward flowing deep western boundary current (DWBC), which has carried a CFC signal higher than 3 pmol kg-1 south to about $45^{\circ} \mathrm{N}$. At $42^{\circ} \mathrm{N}$, such high $\mathrm{CFC}$ values were restricted to a narrow $30-50 \mathrm{~km}$ band at the continental slope (water depth $<2500 \mathrm{~m}$ ) and is only marginally visible in the map. The sharp CFC decrease offshore south of $48^{\circ} \mathrm{N}$ is caused by CFC-poorer water masses from subtropical regions flowing north with the North Atlantic Current (NAC). The limited horizontal extent of the LSW with high CFC concentrations at $42^{\circ} \mathrm{N}$ was also observed in August 1999 (R/V Meteor cruise M45/
3). This southward export of LSW with high CFC values close to the continental slope most likely reflects the fast track of LSW into the subtropical Atlantic (Molinari et al. 1998).

CFC-11 values higher than 3 pmol kg ${ }^{-1}$ are also found in the Irminger Sea, indicative of the rapid spreading of LSW from the formation region to the Irminger Sea (timescale 6 months: Sy et al. 1997). The spreading into the Irminger Sea occurs north of $56^{\circ} \mathrm{N}$ in the opposite direction of the DWBC, which is located at the Greenland continental slope. The relative $\mathrm{CFC}$ maximum in the central Irminger Sea is found at the location of a gyre (inferred from the mean flow field derived from float trajectories (K. Lavender 1999, personal communication)], probably preserving the interior of the gyre from fast exchange with the periphery. There is evidence that deep convection in the Irminger Sea (R. Pickart 1999, personal communication) might be responsible for the CFC maximum there. On the other hand, the years 1995-97 were characterized by weak convection activities, and in the tracer fields of 1999 no CFC maximum was found in the Irminger Sea.

The relatively CFC poor water tongue spreading into the Labrador Sea to about $50^{\circ} \mathrm{W}$ reflects the influence of the NAC, meandering into the Labrador Sea in the "Northwest Corner" (Rossby 1996). Tongues of CFC concentrations between 2.7 and $3.0 \mathrm{pmol} \mathrm{kg}^{-1}$ enter the eastern Atlantic south of $53^{\circ} \mathrm{N}$. Following the trajec- 


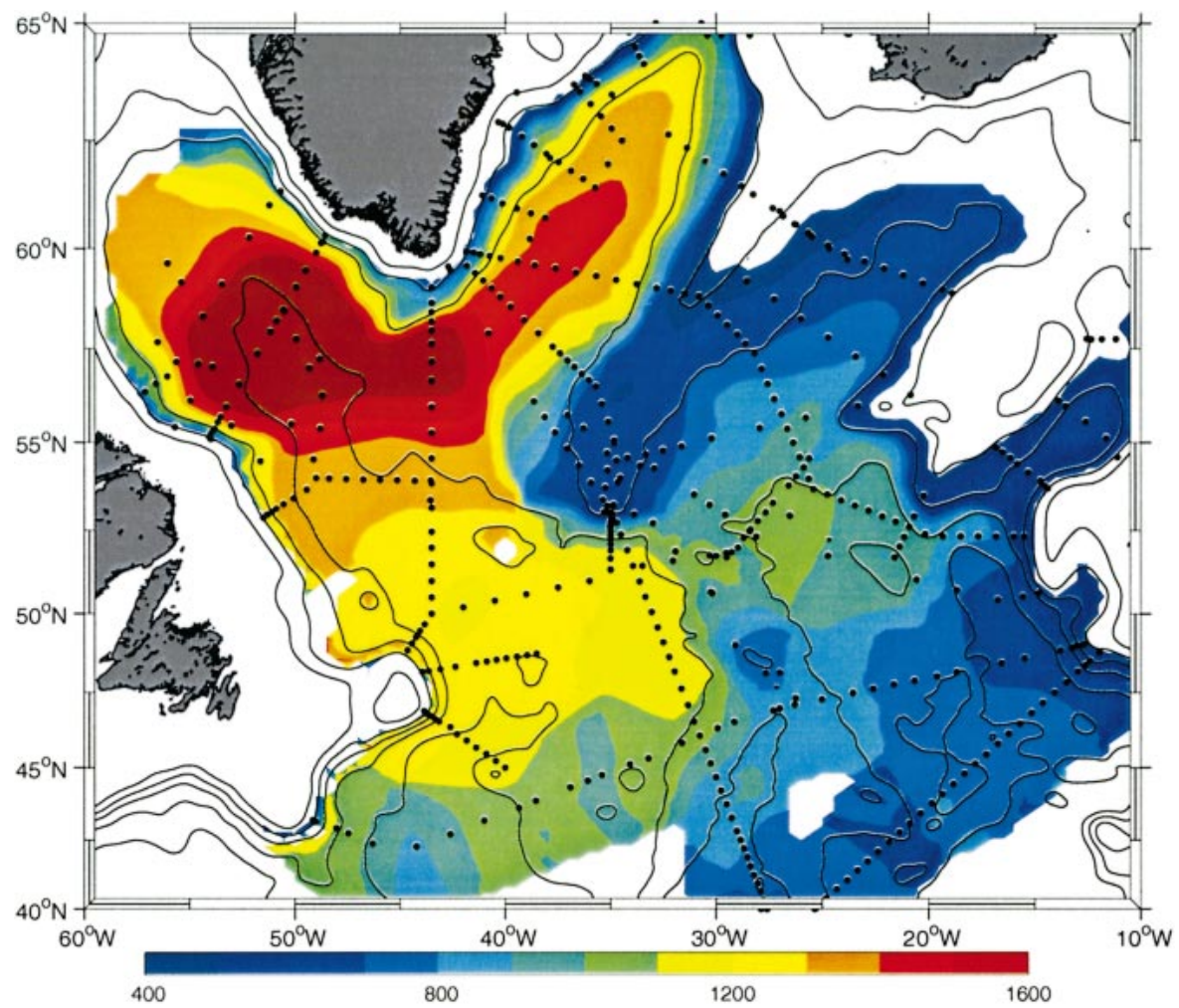

FIG. 9. LSW thickness field interpolated with the procedure published by Davis (1998). A smoothed TBASE topographic dataset was used.

tories of the PALACE floats (Fig. 5), at least a part of this water flows first along the continental slope and at about $50^{\circ} \mathrm{N}$ turns north and east around topographic features (Fischer and Schott 2002) and then turns eastward and crosses into the eastern Atlantic south of $53^{\circ} \mathrm{N}$. The LSW mode proceeding into the eastern Atlantic is CFC poorer and warmer than the LSW spreading into the Irminger Sea due to contributions of the warmer and
CFC-poorer deep extension of the NAC coming from subtropical regions. The LSW crosses the western basin toward the CGFZ in about two years. There is a weak indication that a fraction of the LSW flows southward along the western flank of the Mid-Atlantic Ridge. In Fig. 4, one station located at the eastern flank of the ridge at about $46^{\circ} \mathrm{N}, 31^{\circ} \mathrm{W}$ exhibits significantly higher values than the data in the surrounding area, indicative
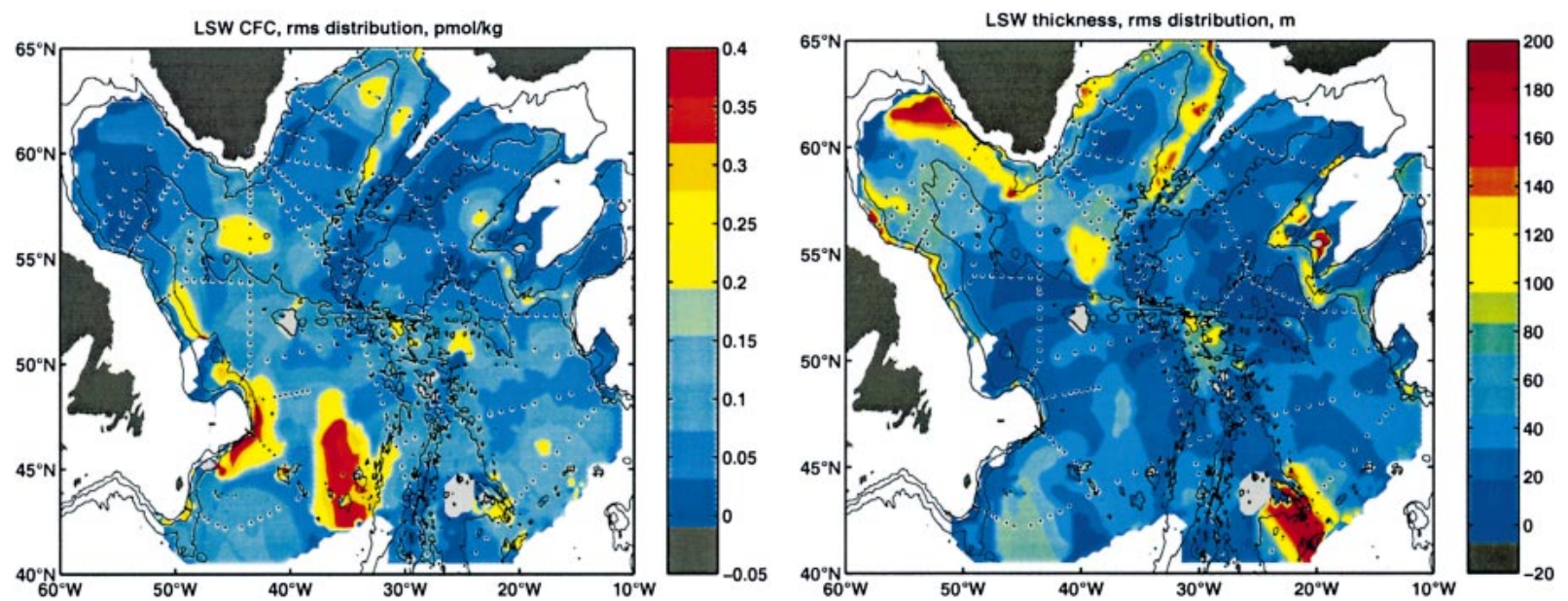

FIG. 10. Spatial distribution of rms from 100 realizations. (a) CFC-11 (pmol kg ${ }^{-1}$ ); (b) LSW thickness (m). The CFC and thickness fields were treated separately since on some stations no CFC data have been analyzed. 
of a southward LSW flow. Due to its small horizontal extension, this feature is not present in the interpolated field.

In the eastern Atlantic, LSW spreads mainly northeastward to the eastern flank of the Iceland Basin, following the approximate path of the North Atlantic Current. One part seems to flow farther east and south into the Porcupine Abyssal Plain, and the CFC concentrations decrease further. Smethie et al. (2000) and Fleischmann et al. (2002) reported that not all ISOW enters the western Atlantic through the CGFZ, but partly flows southward along the eastern flank of the Mid-Atlantic Ridge. It is not yet clear if the LSW also follows this path. The lowest CFC values were found farther south, presumably due to the influence of saline and CFC-poor Mediterranean Water.

The large-scale circulation features summarized by Talley and McCartney (1982) from hydrographic data collected in 1955-64 are similar to the ones reported here. Tongues of low potential vorticity values characteristic for LSW spread from the Labrador Sea northeastward into the Irminger Sea, cross into the northeast Atlantic south of $53^{\circ} \mathrm{N}$, head toward the Rockall Plateau and then east and south into the Porcupine Abyssal Plain, and enter the subtropical gyre in a narrow region close to the continental slope. The southward path along the western flank of the Mid-Atlantic Ridge is not visible in the potential vorticity distribution. Owing to a very coarse resolution in this region, the CFC field there is only weakly constrained by data, and more measurements are needed to confirm this LSW pathway. In the Irminger Sea, the LSW flow scheme that Schmitz and McCartney (1993, their Fig. 11) derived is different from the one inferred from the CFC distribution. The CFC gradients show clearly that the main source of LSW in the Irminger Basin is the Labrador Sea and not the eastern Atlantic.

\section{CFC-11 inventory of the subpolar North Atlantic}

The CFC-11 inventory (INV) of LSW in the subpolar North Atlantic was calculated from the gridded CFC11 and thickness fields by multiplying the average CFC11 concentration $(C)$ and thickness $(D)$ at each grid point by the area $(A)$ of the grid point and the water density and summing over all grid points. The inventories for sLSW, dLSW, and LSW were calculated separately:

$$
\mathrm{INV}=\rho \sum_{i j}\left(C_{i j} \cdot A(i) \cdot D_{i j}\right)
$$

$$
\begin{array}{ll}
C_{i j} & \text { CFC concentration }\left(\mathrm{pmol} \mathrm{kg} \mathrm{kg}^{-1}\right) \text { at location lat }(i), \operatorname{lon}(j) \\
D_{i j} & \text { thickness }(\mathrm{m}) \text { at location lat }(i), \operatorname{lon}(j) \\
i & \text { latitude, } 40^{\circ} \mathrm{N}-65^{\circ} \mathrm{N} \\
j & \text { longitude, } 60^{\circ} \mathrm{W}-10^{\circ} \mathrm{W} \\
A & \text { area of grid point }\left(0.25^{\circ} \text { lat } \times 0.5^{\circ} \text { lon }\right) \text { in } \mathrm{m}^{2} \\
\rho & \text { water density in } \mathrm{kg} \mathrm{m}^{-3} .
\end{array}
$$

The CFC-11 inventory for LSW is $16.6 \pm 1.8$ million moles, which is equivalent to $2300 \pm 250$ tons (Table 2). About $69 \%$ of the inventory is found in the western basin and $31 \%$ in the eastern basin, although the areas where LSW is present are similar for both basins; $28 \%$ of the inventory is still located in the Labrador Sea west of $45^{\circ} \mathrm{W}$. The higher inventory in the western basin is caused by a greater thickness (Fig. 8) of the LSW layer (western basin: $1210 \mathrm{~m}$, eastern basin: $740 \mathrm{~m}$ ) and by the higher $\mathrm{CFC}-11$ concentrations in most of the western North Atlantic (Fig. 7). The contributions of both sLSW and dLSW reflect the LSW formation and input of CFC11 in the western basin and the fast spreading of LSW into the Irminger Sea and southward in the DWBC. The CFC-11 inventory in the dLSW is higher than in sLSW. This feature mainly reflects the different thicknesses of the layers: the sLSW has a mean thickness of $410 \mathrm{~m}$, the dLSW of $600 \mathrm{~m}$. Following the temporal trends, the inventory of the eastern Atlantic should increase in the next years, and as long as the deep convection in the Labrador Sea is not intensified, the CFC inventory in the western Atlantic should decrease. Smethie and Fine (2001) estimated the CFC-11 inventory in LSW for the subpolar North Atlantic in 1990 to be 12.4 million moles. This is smaller than our value and shows that CFCs continued to enter LSW between 1990 and 1997 faster than they were exported out of the subpolar gyre.

\section{a. Uncertainties in the inventory}

Compared to the CFC inventory calculations from Smethie and Fine (2001), the observations in 1997 have various advantages. The dataset is much larger, so that the CFC distribution in LSW can be studied in more 
TABLE 2. CFC-11 inventory (million moles) in the density layers of LSW for 1997 in the western and eastern North Atlantic, 40 $65^{\circ} \mathrm{N}$. The inventory of the total LSW is not the exact sum of sLSW and dLSW because the inventory for total LSW has been calculated independently.

\begin{tabular}{lccc}
\hline \hline $\begin{array}{c}\text { Density layer } \\
\sigma_{\theta}\end{array}$ & $\begin{array}{c}\text { Total } \\
\text { inventory } \\
\left(10^{6} \text { moles }\right)\end{array}$ & $\begin{array}{c}\text { Western } \\
\text { Atlantic } \\
\left(10^{6} \text { moles }\right)\end{array}$ & $\begin{array}{c}\text { Eastern } \\
\text { Atlantic } \\
\left(10^{6} \text { moles }\right)\end{array}$ \\
\hline sLSW (27.74-27.77) & $7.0 \pm 0.9$ & $4.5 \pm 0.6$ & $2.5 \pm 0.4$ \\
dLSW (27.77-27.80) & $9.9 \pm 1.3$ & $7.4 \pm 0.9$ & $2.5 \pm 0.4$ \\
LSW (27.74-27.80) & $16.6 \pm 1.6$ & $11.7 \pm 1.4$ & $4.8 \pm 0.7$ \\
\hline
\end{tabular}

detail, and the errors in the inventories can be better assessed. Since the data are synoptic, the measured CFC concentrations and the LSW thickness fields need not be normalized to a common date. We have shown that from 1991-97 the temporal evolution of the CFC and the thickness fields are regionally different and the latter procedure would be difficult to apply.

We already have assessed the uncertainty in the CFC11 and thickness fields. The uncertainties of the CFC11 inventories from the combined error on the CFC-11 and thickness fields was calculated to $\pm 10 \%$ (LSW), $12 \%$ (dLSW), and 14\% (sLSW).

\section{b. Error from incompleteness of the gridded fields}

CFC concentrations and LSW thickness values could not be calculated on some grid points due to lack of observations. About $12 \%$ of these grid points have water depths greater than $1000 \mathrm{~m}$, so we can certainly assume that LSW is present. Here 1.4\% are located in the high $\mathrm{CFC}$ and high thickness region of the northern Labrador Sea, but the majority are in the southernmost part of the western and eastern basins, which are both low CFC and low thickness regions (Figs. 8 and 9). Extrapolating the CFC and thickness fields from the surrounding areas to fill these regions, the northern Labrador Sea may add another $3.6 \%$ to the CFC inventory and the other areas could contribute 3\% (mean thickness 700 m, mean CFC $1 \mathrm{pmol} \mathrm{kg}{ }^{-1}$ ). Both contributions were neglected in the CFC inventory shown in Table 2. If we take them into account, the CFC inventory increases to $17.7 \times 10^{6}$ moles.

\section{c. Error from the nonsynopticity of the data}

Another error might arise from the large-scale nonsynopticity of the dataset. As already discussed, the LSW variability (1994-97) in the western Atlantic north of $50^{\circ} \mathrm{N}$ is dominated by a thickness decrease of about 100-200 m yr ${ }^{-1}$ (Irminger Sea, Labrador Sea), the region south of $50^{\circ} \mathrm{N}$ by a CFC increase of $0.05-0.1 \mathrm{pmol}$ $\mathrm{kg}^{-1} \mathrm{yr}^{-1}$, and the eastern Atlantic by a CFC-11 increase of $0.2-0.3 \mathrm{pmol} \mathrm{kg}^{-1} \mathrm{yr}^{-1}$. However, the thickness and CFC-11 fields in the Labrador Sea are already composites of three cruises (Table 1). From the FebruaryMarch cruise (1997), all profiles where the density in the upper $300 \mathrm{~m}$ exceeds $\sigma_{\Theta}=27.74$ were omitted from the thickness calculations and the calculation of the CFC fields. The fields in the Irminger Sea and in the eastern Atlantic north of $50^{\circ} \mathrm{N}$ are a composite of four cruises. For all these regions, the effect of the nonsynopticity is already covered by the jackknifing procedure.

South of $50^{\circ} \mathrm{N}$, spatial resolution is coarser, and the fields are determined from only two cruises and from two sections in the western Atlantic carried out in August 1996. The contribution of the area south of $50^{\circ} \mathrm{N}$ to the CFC-11 inventory $\left[\sigma_{\Theta}=27.74(+0.06)\right]$ is $30 \%$, with $18 \%$ from the western basin and $12 \%$ from the eastern basin. The annual repeat sections along WOCE line A2 (nominally $48^{\circ} \mathrm{N}$ ) do not show a temporal trend of the LSW thickness but, as mentioned above, a CFC increase that is stronger in the eastern basin. A CFC11 increase of $0.05 \mathrm{pmol} \mathrm{kg}^{-1}$ per 5 months in the western Atlantic south of $50^{\circ} \mathrm{N}$ and of $0.15 \mathrm{pmol} \mathrm{kg}^{-1}$ per 5 months in the eastern Atlantic south of $50^{\circ} \mathrm{N}$ would increase the inventory of these areas by roughly $2.5 \%$ and $10 \%$, respectively. The total CFC-11 inventory would then increase by about $2 \%$. Thus, we estimate the error arising from the large-scale nonsynopticity of the data to be smaller than $3 \%$ and negligible compared to the other uncertainties.

\section{Discussion}

\section{a. Assumptions for calculating LSW formation rates}

The CFC-11 inventory is used to estimate a lower limit of LSW production. For this purpose it is assumed that all CFC-11 in the LSW layer was introduced by the process of deep convection. The exact site of the formation area is irrelevant to the calculations.

If this assumption is true, the CFC- 11 concentrations should increase with decreasing salinity in the subpolar North Atlantic, since the water masses surrounding LSW are in general CFC poorer and more saline than LSW. Figure 11 presents the CFC-11-salinity correlation of the observations used for the calculation of the inventory. The dominating correlation is an inverse linear relationship between CFC-11 and salinity. The two linear mixing lines between the salinity minimum of LSW and the upper water column and between the salinity minimum and the deeper waters cannot be distinguished.

However, there are three deviations from the linear correlation representing LSW (Fig. 11). The lowest branch, at CFC-11 $=1.2-1.5 \mathrm{pmol} \mathrm{kg}^{-1}$, is located in the eastern Atlantic south of $46^{\circ} \mathrm{N}$ (blue dots in Fig. 11) and indicates mixing with saline Mediterranean Water with CFC-11 concentrations around $1.5 \mathrm{pmol} \mathrm{kg}{ }^{-1}$. The area where this correlation is found is small and does not significantly contribute to the inventory $(<5 \%)$. Moreover, the higher CFC-11 concentrations in this area do follow the LSW correlation.

The deviation at about $2.5 \mathrm{pmol} \mathrm{kg}^{-1}$ (red dots in 
red: EAt $>58 \mathrm{~N}$, blue: $E A t<46 \mathrm{~N}$, green:Wat $>60 \mathrm{~N}$, west $37 \mathrm{~W}$

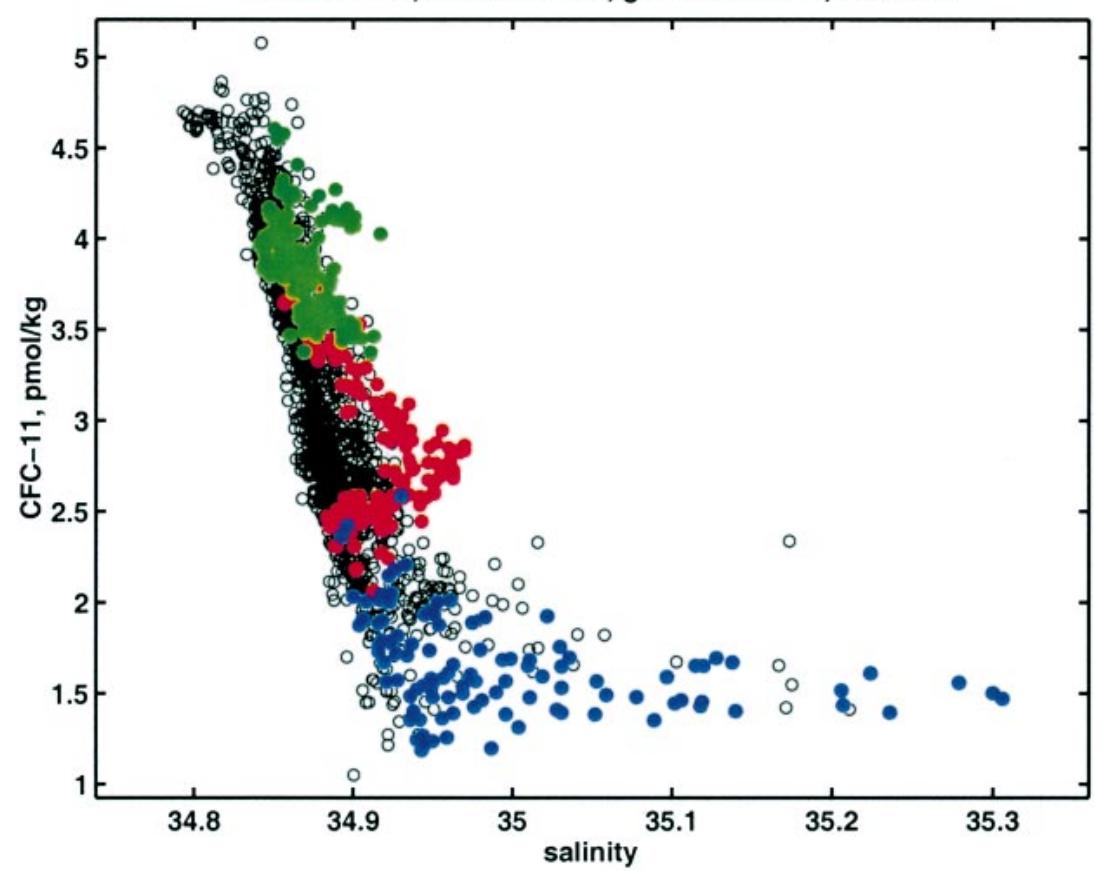

FIG. 11. CFC-11 salinity correlation for $\operatorname{LSW}\left(\sigma_{\Theta}=27.74-27.80\right)$. All data are presented (open circles). Red: eastern Atlantic, north of $58^{\circ} \mathrm{N}$; blue: eastern Atlantic, south of $50^{\circ} \mathrm{N}$; green: western Atlantic at the Greenland continental slope, north of $60^{\circ} \mathrm{N}$.

Fig. 11) indicates mixing of LSW with ISOW north of $58^{\circ} \mathrm{N}$ at the eastern flank of the Reykjanes Ridge. Here again, the area involved is small, the LSW thickness is only 100-200 m (Fig. 8b), and the higher CFC-11 concentrations tend to follow the LSW correlation. Farther south, the linear LSW correlation prevails.

The third deviation at about $4.2 \mathrm{pmol} \mathrm{kg}^{-1}$ (green dots in Fig. 11) is caused by mixing of sLSW with saline water of Atlantic origin, located between the cold and fresh East Greenland Current and the LSW. The mixing occurs at the Greenland continental slope north of $60^{\circ} \mathrm{N}$ in a small area and is not observed farther south.

We conclude from the dominating LSW correlation between CFC-11 and salinity that the contributions to the CFC-11 inventory by mixing with Mediterranean Water south of $46^{\circ} \mathrm{N}$, with Iceland-Scotland overflow water north of $48^{\circ} \mathrm{N}$ (eastern Atlantic), and with Atlantic Water north of $60^{\circ} \mathrm{N}$ (western Atlantic) are small and can be neglected in the calculations of the LSW formation rates. The import of water from the subtropical gyre by the deep extension of the NAC is recirculated LSW plus some mixture of other water masses, but the latter are CFC poor and their impact can be neglected.

We define the subpolar North Atlantic as a closed basin where the densities that bound the LSW, the sLSW, and the $\mathrm{dLSW}\left(\sigma_{\Theta}=27.74,27.77\right.$, and 27.80) are material surfaces outside the LSW formation region. Only one source of CFC exists for the LSW, and that is deep convection in the Labrador Sea. During convection, the water located above the LSW becomes denser than
$\sigma_{\Theta}=27.74$ and is thus a new volume of LSW. Note that in this calculation the term "newly formed LSW" means the water volume that was less dense than LSW before convection starts and is then transferred to the density classes of LSW by buoyancy loss. It should not be mistaken as the conversion of a warmer, saline, and CFC poorer LSW to a colder, less saline, and CFC richer LSW mode. This is shown in Fig. 12. As an example, the density and CFC profiles from the central Labrador Sea (cruise M39-4, see Table 1) are presented in Figs. $12 \mathrm{a}$ and $12 \mathrm{~b}$. The sharp increase in the CFC concentrations is caused by the warm summer surface layer overlying the colder layers below. The LSW bounded by the isopycnals 27.74-27.80 is shaded and extends from 600 to $2300 \mathrm{~m}$. Figure $12 \mathrm{c}$ shows the density profile after deep convection to about $1900 \mathrm{~m}$. The water column above $600 \mathrm{~m}$ is now denser than $\sigma_{\Theta}=27.74$ and is thus a new volume of LSW that is added to the "old" LSW volume. The water below $600 \mathrm{~m}$ is modified-it becomes cooler, fresher and CFC richer-but it is only a conversion between LSW modes, and the higher CFC values come from the mixing with the new volume of LSW.

\section{b. CFC saturation of new LSW}

Observations in February-March in deep convection regions of the Greenland Sea have shown that in the intermediate deep mixed layer before the onset of deep convection (i.e., before deep convection reaches the den- 

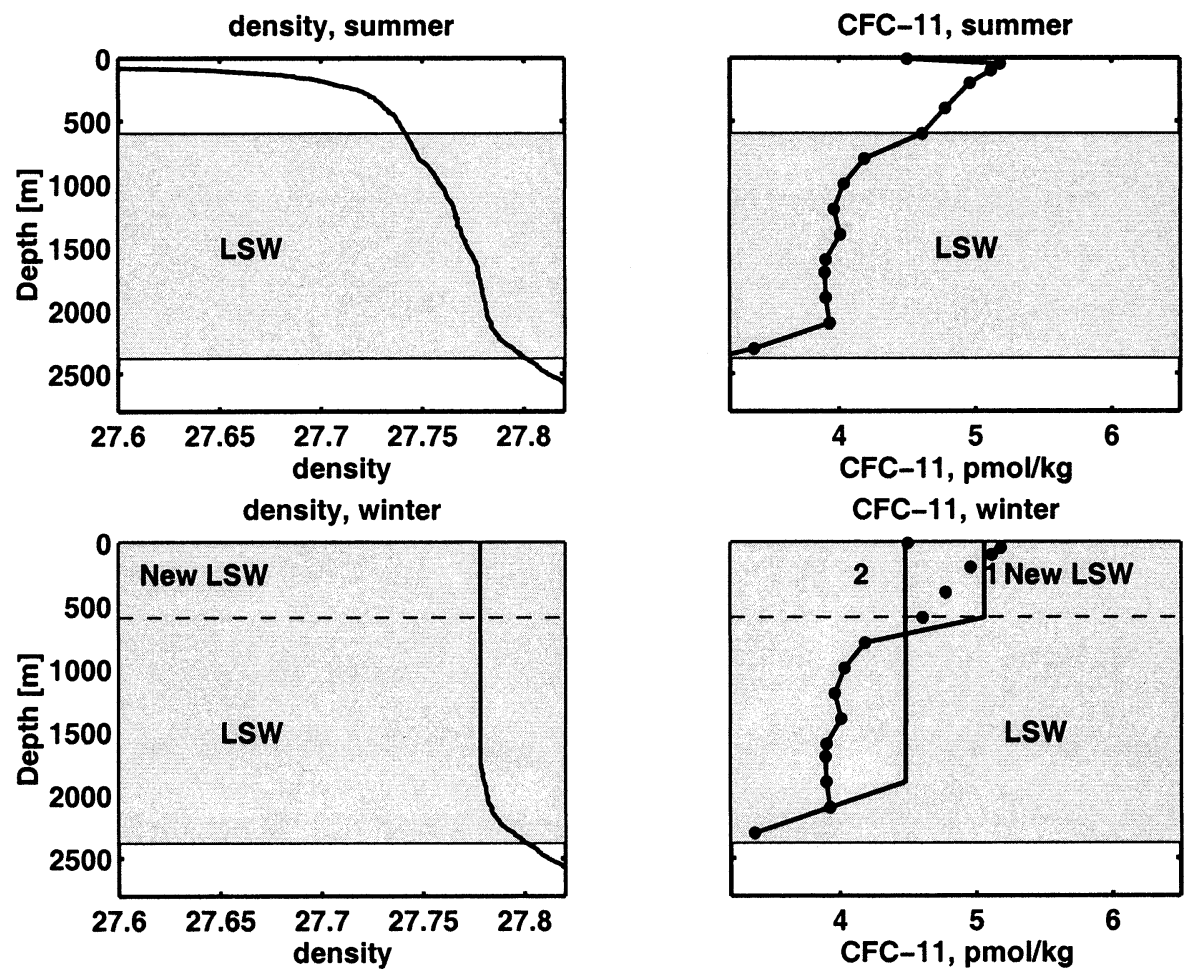

FIG. 12. Schematic view of the density profiles for summer (a) and winter (c) and the CFC profiles in summer (b) and winter (d).

sity layers of LSW) the water is saturated to about $80 \%$ (Rhein 1991, 1996). The integral effect of deep convection is a vertical homogenization of the CFC profile from the surface to the convection depth. In the example of the Labrador Sea in Fig. 12d, a convection depth of $1900 \mathrm{~m}$ is assumed. The additional CFC introduced in the old LSW, however, originates from the upper 600 $\mathrm{m}$ (the new LSW volume) that was mixed with the old LSW, and the CFC saturation of the upper $600 \mathrm{~m} \mathrm{de-}$ creases during convection (profile 2, Fig. 12d).

Low CFC saturations of $40 \%-60 \%$ are observed in the convected water column-including the surface water-in the Labrador Sea (Wallace and Lazier 1988; Smethie et al. 2000) as well as other regions (Rhein 1995) because the timescale of convection (days) is too short to allow for air-sea gas exchange to significantly raise the concentration before the convection cell is capped by less dense surface water. In February-March 1997 in the central Labrador Sea, the CFC profiles with surface densities greater than $\sigma_{\Theta}=27.74$ (11 profiles) had mean CFC-11 concentrations in the upper $2000 \mathrm{~m}$ of $4.29 \pm 0.11 \mathrm{pmol} \mathrm{kg}^{-1}$, and the profiles with lower surface densities had mean values of $4.07 \pm 0.16$ pmol $\mathrm{kg}^{-1}$, indicating that the air-sea gas exchange during convection might add about $5 \%$ to the CFC-11 content. The mean CFC-11 saturation in the upper $500 \mathrm{~m}$ of the profiles with surface densities less than $\sigma_{\Theta}=27.74$ (i.e., no convection below $500 \mathrm{~m}$ ) was found to be $79.3 \% \pm$ $2.1 \%$ (4.6 pmol kg-1). Combining these data led us to the assumption that the water above the LSW prior to convection is saturated to $85 \%$. Note that the CFC saturation in the water above the LSW is used for the calculations (i.e., before LSW formation starts), not the saturation of the already convected water column (40\%$60 \%)$.

The formation rates of new LSW were calculated with this boundary condition. Although the stratification within the LSW is weak and a smoothing of the vertical CFC gradient between sLSW and dLSW away from the formation region is observed, we present sLSW and dLSW formation rates separately. This is somewhat artificial since in the calculations the isopycnal $\sigma_{\Theta}=27.77$ is treated as a material surface. In doing so and assuming that the dLSW is only formed in years with a high NAO index, the difference between the production rates in years with weak LSW production (low NAO index, only SLSW is formed) and with high LSW production (high NAO index, sLSW and dLSW is formed) can be estimated.

\section{c. Model calculations}

For the sake of simplicity, we first ignore the temporal variability in the LSW formation rate. The formation rate is assumed to be constant, and the saturation of newly formed LSW is set to $85 \%$. As already mentioned, the subpolar North Atlantic is regarded as a closed basin where the densities that bound the LSW, the sLSW, and 
TABLE 3. LSW formation rates (Sv) for 1988-97.

\begin{tabular}{lccc}
\hline \hline \multicolumn{1}{c}{ LSW formation } & sLSW & dLSW & sLSW + dLSW \\
\hline$R=$ const, sat $=85 \%$ & $1.8-2.4$ & $2.6-3.4$ & $4.4-5.6$ \\
$R=$ const, sat $=75 \%$ & $2.0-2.7$ & $2.9-3.8$ & $5.0-6.3$ \\
$R=$ const, sat $=60 \%$ & $2.6-3.4$ & $3.6-4.8$ & $6.2-7.9$ \\
dLSW only formed during high NAO & $1.8-2.4$ & $6.4-8.5$ & $8.1-10.8$ \\
LSW formation rate 1995-97 & $1.8-2.4$ & - & $1.8-2.4$ \\
\hline
\end{tabular}

the dLSW $\left(\sigma_{\Theta}=27.74,27.77\right.$, and 27.80) are the material surfaces outside the LSW formation region. The only CFC source of LSW is by deep convection. The atmospheric CFC concentrations are taken from $R$. Weiss (SIO) [for a discussion see Walker et al. (2000)]. For a constant annual LSW formation rate $R$ the equation is

$$
R=\frac{\mathrm{CFC}_{\mathrm{inv}}}{\rho \int_{1930}^{1997}(C(t) \times 0.85) d t},
$$

where $\mathrm{CFC}_{\text {inv }}$ is the 1997 CFC inventory for LSW, sLSW, or dLSW, respectively; $\rho$ is the density of seawater; $C(t)$ is the CFC concentration in water $(\Theta=$ $\left.2.8^{\circ} \mathrm{C}\right)$, which is in equilibrium with the atmospheric concentration in year $t(t=1930 \ldots 1997)$; and 0.85 is the CFC-saturation degree of newly formed LSW.

At a saturation of $85 \%$, the annual mean formation rate of new LSW lies between 4.4 Sv and 5.6 Sv. The formation rate is divided into 2.6-3.4 Sv dLSW and 1.8-2.4 Sv sLSW. These estimates are the lower limit of a mean LSW formation rate compatible with the CFC inventory in 1997. Including the estimated CFC inventory from regions where the CFC and thickness fields could not be interpolated from the observations, the mean LSW formation rate is 4.7-6.0 Sv.

In our model run with a constant LSW formation rate, $32.7 \%$ of the CFC inventory was introduced into the LSW layer during the last seven years (1991-97), and in 1990 the CFC-11 inventory was 11.2 million moles. This value is lower by 1.2 million moles than the CFC11 inventory Smethie and Fine (2001) estimated for the subpolar North Atlantic (12.4 million moles) from the 1986-92 CFC-11 dataset.

Due to the exponential increase of the CFC concentrations from 1930 to mid-1975 and the linear increase thereafter, $56.4 \%$ of the inventory entered between 1970 and 1990 , and $11 \%$ originate from the time period 193070. Thus, although our calculation is for 1930-97, our results are mainly representative for the period 197097. If a major part of the inventory had come from the years before 1970, the assumption that the subpolar North Atlantic is a closed basin would not be appropriate, since the flushing time of the subpolar North Atlantic is in the order of 20-50 years.

A formation rate of $5 \mathrm{~Sv}$ new LSW equals a volume of $16 \times 10^{13} \mathrm{~m}^{3} \mathrm{yr}^{-1}$. Assuming that the water (less dense than LSW before convection) above the LSW extends to depth $500 \mathrm{~m}$ before convection starts, the convection area in the Labrador Sea is calculated to 30 $\times 10^{4} \mathrm{~km}^{2}$ (circle with radius $309 \mathrm{~km}$ ). Lilly et al. (1999) report a region of about $500 \mathrm{~km} \times 600 \mathrm{~km}$ where deep convection could take place in the Labrador Sea, comparable to the aforementioned area. If we assume that the newly formed LSW remains in the western subpolar North Atlantic north of $50^{\circ} \mathrm{N}$ for one year (area with water depth $>1500 \mathrm{~m}: 2 \times 10^{12} \mathrm{~m}^{2}$ ), a LSW production of $5 \mathrm{~Sv}$ would require a mean annual LSW thickness increase of $70 \mathrm{~m}$, and thickness changes like that have been observed (Curry et al. 1998).

The monitoring of subsurface conditions in the Labrador Sea provides evidence of increased and deepening ventilation, and increasing production of LSW in 197276 and in 1988-94 (Dickson et al. 1996; Sy et al. 1997). We repeat the above calculations, but with the assumption that the dense LSW mode, the dLSW $\left(\sigma_{\Theta}=27.77-\right.$ 27.80), was only formed in 1930-60, 1972-76, and 1988-94. As already mentioned, the time period before 1970 is not relevant for the CFC inventory in 1997; the contribution of this time period is marginal no matter what the convection intensity was.

The dLSW production in 1988-94 is calculated to 6.4-8.5 Sv; the sLSW formation rate is kept constant at $1.8-2.4 \mathrm{~Sv}$. The total $\mathrm{LSW}$ production rate in the years 1988-94, are then calculated to 8.1-10.8 Sv (sLSW and dLSW), and in 1995-97 the production rate decreases to 1.8-2.4 Sv. One has to keep mind that the calculated formation rates are directly dependent on the assumed CFC saturation in newly formed LSW. A saturation degree of $75 \%$ enhances the calculated mean LSW formation rate $0.5-0.7 \mathrm{~Sv}$, and a saturation degree of $95 \%$ decreases the formation rate by about the same amount (Table 3).

\section{d. Export of LSW south of $40^{\circ} \mathrm{N}$}

One of the assumptions in calculating the LSW formation rate was that the subpolar North Atlantic is a closed basin for LSW. This is not entirely true. There is clear evidence of a relatively fast southward spreading of the CFC signal, and new LSW formed after 1988 reached the subtropical Atlantic $\left(26.5^{\circ} \mathrm{N}\right)$ in $1996(\mathrm{Mol}-$ inari et al. 1998). In 1990, Smethie and Fine (2000) estimated that up to $15 \%$ of the CFC inventory in LSW was south of $40^{\circ} \mathrm{N}$. An increase of the subtropical fraction is expected since CFC-rich LSW flowed southward with the DWBC in 1991-97. 


\section{e. CFC transfer to higher-density classes by entrainment}

After overflowing Denmark Strait the transport of the DSOW increases from 2.9 Sv to $5.1 \mathrm{~Sv}$ by entrainment (Dickson et al. 1996). Part of the entrained water might be CFC-rich LSW, which by this process is transferred to water with a higher density than $\sigma_{\Theta}=27.80$. The major part of the entrainment, however, occurs at still depth $(600 \mathrm{~m})$ or slightly below (Price and O'Neil-Baringer 1994), and the depth of the upper boundary of LSW, the $\sigma_{\Theta}=27.74$ layer, is found at depth $900 \mathrm{~m}$ south of Denmark Strait at $64^{\circ} 40^{\prime} \mathrm{N}$ : it cannot be discounted, that part of the entrained water might be LSW.

Entrainment of LSW might also occur south of the sills between Iceland and Scotland. Smethie et al. (2000) estimated from temperature and salinity data that the composition of ISOW after entrainment contains about $35 \%$ LSW and 20\% northeast Atlantic water. Harvey and Theodorou (1986) reported 25\% LSW, and Swift (1984) and Smethie and Swift (1989) found no LSW contribution, but mixing of $59 \%$ ISOW and $41 \%$ northeast Atlantic water. A multivariate analysis by D.-H. Min resulted in a $16 \% \mathrm{LSW}$ contribution to ISOW.

To summarize, the amount of LSW and the amount of CFCs transferred to higher-density classes through entrainment is open to debate. Smethie and Fine (2001) estimated that about $1.8 \mathrm{~Sv} \mathrm{LSW}$ are transferred to higher-density classes by entrainment east of the Reykjanes Ridge and that no LSW is entrained into DSOW.

\section{f. Comparison with other estimates of LSW formation}

The calculated and estimated LSW formation rates are summarized in Table 3. In total, assuming constant LSW formation rates, 4.4-5.6 Sv new LSW are required to cover the CFC inventory in the LSW layer in the North Atlantic. If dLSW is only formed in high NAO index periods, the LSW formation rate in 1988-94 is 8.1-10.8 Sv, decreasing to $1.8-2.4 \mathrm{~Sv}$ in 1995-97.

Smethie and Fine (2001) did similar calculations for the period before 1990, with a much more limited and nonsynoptic CFC dataset collected between 1986 and 1992. Their boundary condition for CFC input was different from ours in two major ways: 1) they used a CFC11 saturation of the deep convective layer of $60 \%$, which was measured while deep convection took place; and 2) they excluded the CFC-11 inventory in the region of formation in the central Labrador Sea since their calculation yielded a transport out of the formation region, which was assumed to be at $60 \%$ saturation. Assuming a constant formation rate, Smethie and Fine (2000) obtained 7.6 Sv, which is higher than our estimate of 4.45.6 Sv. They obtained higher rates because of their high CFC-11 inventory in 1990 (12.4 million moles) compared to the model calculations here (11.2 million moles), by including the CFC-11 inventory south of $40^{\circ} \mathrm{N}$ $(15 \%)$, and by the different choice of the boundary con- ditions. Smethie and Fine (2001) also estimated the formation rate assuming it varied a factor of 10 between high and low formation years and scaled to the thickness of LSW. For the 1970-90 period they obtained minimum, maximum, and average formation rates of $1.3 \mathrm{~Sv}$, 12.5 Sv, and 7.4 Sv. Reducing these values for the CFC11 inventory south of $40^{\circ} \mathrm{N}$ yields $1.1 \mathrm{~Sv}, 10.6 \mathrm{~Sv}$, and $6.3 \mathrm{~Sv}$. Our ratio between low and high formation rates turned out to be 1:5. This estimate is representative for the time period 1970-97.

Our estimates of 8.1-10.8 Sv (1988-94) and 1.8-2.4 Sv (1995-97) are comparable to the LSW overturning rates of 5-10 Sv for 1988-94 and to 1-3 Sv for 199597 that Marsh (2000) inferred from surface fluxes while neglecting mixing. One has to take into account that the LSW boundaries were chosen differently: Marsh (2000) defined the LSW bounded by $\sigma_{\Theta}=27.65-27.775$ compared to 27.74-27.80 (this study). As mentioned before, our calculated LSW formation rates are a lower limit. This might also be true for the Marsh (2000) values: model studies of Nurser et al. (1999) show that when mixing is neglected, the LSW formation rates tend to be lower than the true rate.

\section{Summary and conclusions}

The CFC-11 and CTD dataset from 1997 in the subpolar North Atlantic is discussed in conjunction with the PALACE float trajectories to study the pathways, the CFC inventory, and formation rates of LSW. Five different scientific groups were involved in the data sampling, and the CFC dataset is found to be consistent at a $4 \%$ level. The synopticity of the data was studied by examining the temporal trends for repeated sections during the 1991-98 period. Between 1994 and 1997, the LSW in the western subpolar Atlantic north of $50^{\circ} \mathrm{N}$ is mainly affected by thickness changes of 100-200 m $\mathrm{yr}^{-1}$, and south of $50^{\circ} \mathrm{N}$ and in the eastern Atlantic, the regionally different increase of CFCs of 0.05-0.3 pmol $\mathrm{kg}^{-1} \mathrm{yr}^{-1}$ is more important. The LSW thickness decrease north of $50^{\circ} \mathrm{N}$ is roughly equivalent to a $\mathrm{LSW}$ volume loss of $10 \mathrm{~Sv}$.

Since both the CFC contours and the float trajectories mainly follow $f / H$ contours, a topography-following interpolation scheme (Davis 1998) is applied to calculate gridded fields of CFC concentrations and LSW thickness. The interpolation scheme preserves the sharp gradients across isobaths. We used the gridded CFC and thickness fields to calculate the CFC inventory of LSW in 1997 with unprecedented small errors (10\%-14\%). In 1997 , about $28 \%$ of the inventory was still in the Labrador Sea west of $45^{\circ} \mathrm{W}$, and $31 \%$ of the inventory had already intruded the eastern Atlantic (Fig. 13). Following the present temporal trends, the inventory of the eastern Atlantic is expected to increase in coming years, and the CFC inventory in the western Atlantic north of $50^{\circ} \mathrm{N}$ will decrease, as well as the volume of LSW. Since the CFCs present in the LSW layer were introduced by 


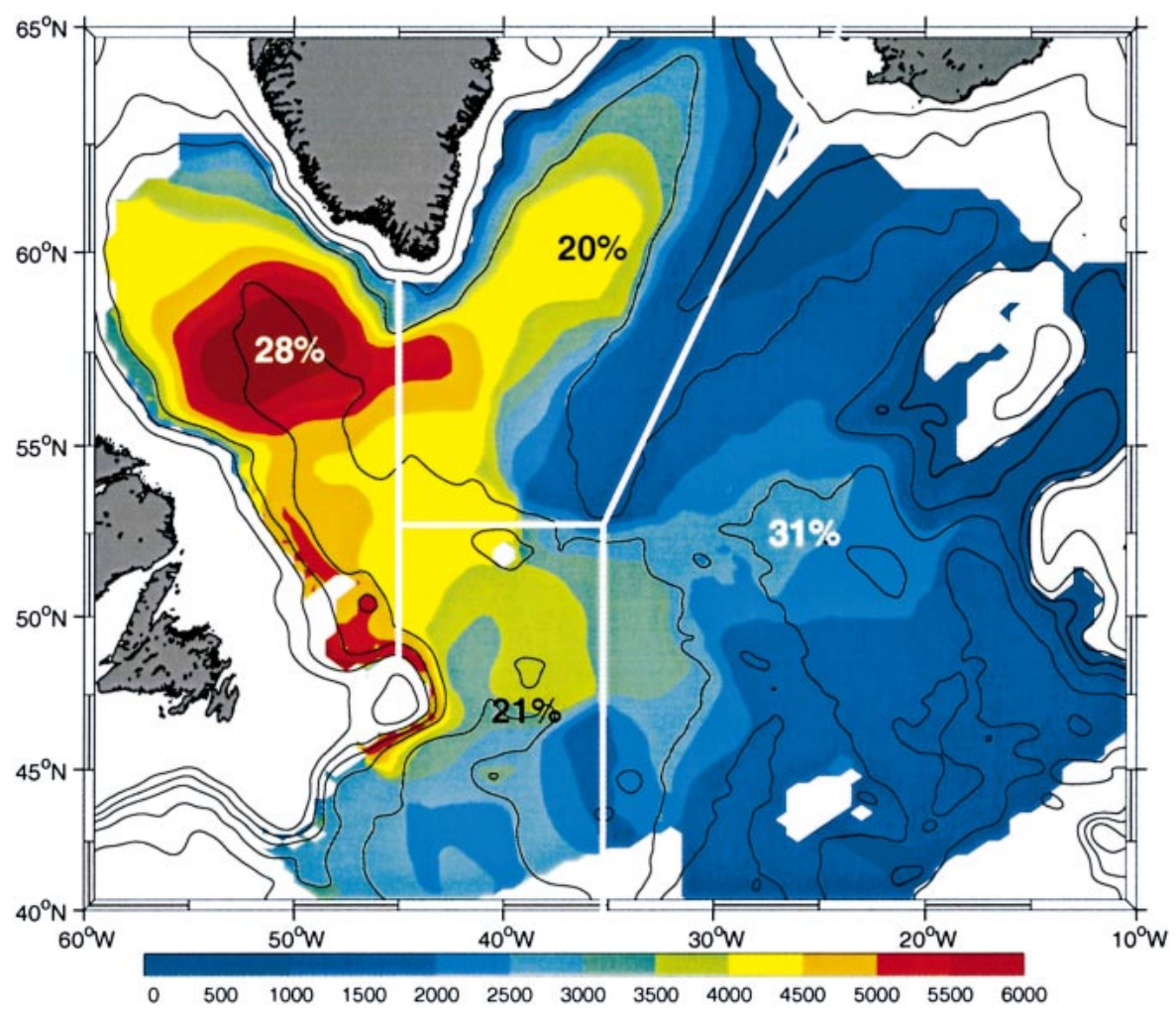

FIG. 13. CFC inventory of LSW in the subpolar North Atlantic, 1997. The color scale is in moles normalized to the grid area $\left(0.25^{\circ}\right.$ lat by $\left.0.5^{\circ} \mathrm{lon}\right)$. The numbers within the figure denote the percentage of the inventory in the enclosed areas.

deep convection, the CFC inventory can be used to estimate lower limits of the LSW formation rates. For the calculations, we combined previous observations in deep convection regions with the Labrador Sea winter data of 1997 and estimated a CFC saturation in the "new" LSW volume of $85 \%$. Furthermore, we assumed that the subpolar North Atlantic is a closed basin for LSW and that the isopycnals that bound the LSW are material surfaces. The LSW formation rate calculated for the time period 1988-97 is a lower limit. The mean LSW formation rate necessary to account for the CFC inventory in 1997 in the subpolar North Atlantic north of $40^{\circ} \mathrm{N}(2300 \pm 250$ tons CFC) was calculated as 4.4$5.6 \mathrm{~Sv}$. For about $12 \%$ of the area with water depth greater than $1000 \mathrm{~m}$ the $\mathrm{CFC}$ and thickness fields could not be interpolated. Estimating the CFC inventory of these areas by extrapolating from neighboring regions, the CFC inventory for the subpolar North Atlantic increases by $6 \%-7 \%$. If one takes these regions into account, the mean LSW formation rate is calculated as 4.7-5.9 Sv.

If the denser modes of LSW are only formed in years with high NAO index, the formation rate is calculated as $8.1-10.8 \mathrm{~Sv}$ in $1988-94$ and $1.8-2.4 \mathrm{~Sv}$ in $1995-97$. A shift in the saturation degree of $10 \%$ would alter the calculated formation rates by about $0.5-0.7 \mathrm{~Sv}$.

Future measurements in the subpolar North Atlantic will benefit from the 1997 fields to evaluate the regionally different temporal evolution of the LSW characteristics and to study the ventilation of LSW. The interpolation method can easily be extended to other water masses in the subpolar North Atlantic, namely to study the spatial distribution of the ISOW and DSOW characteristics. One could also calculate the $\mathrm{CO}_{2}$ inventory of the subpolar North Atlantic by applying the almost linear relationship between $\mathrm{CO}_{2}$ and $\mathrm{CFC}$ in this region (Körtzinger et al. 1999). Tracer and inventory fields like the ones presented here can also be used to assess some key aspects in ocean models. One key aspect is the representation of water mass formation since this process links surface water variability (and thus climate variability) to the deep ocean and strongly influences the poleward heat and freshwater transports.

Acknowledgments. We thank captains, crews, and chief scientists of the cruises Knorr 147, Knorr 151/2, Discovery 230, Valdivia 161, 172, and Meteor 30, legs 2,3 , and cruise 39 , legs $2-5$. We thank K. P. Koltermann, R. Pickart, F. Schott, and A. Sy for providing CTD data. R. Weiss thanks F. A. Van Woy, M. K. Vollmer, and P. K. Salameh for their contributions to the Knorr 151 expedition work and to the CFC data processing. W. M. Smethie would like to thank G. Mathieu for singlehandedly measuring the CFC samples on the winter Lab- 
rador Sea cruise Knorr 147 and E. Gorman and H. Lee for processing the final data. D. Smythe Wright would like to thank S. M. Boswell and C. R. Harris for their substantial help with the expedition work on Discovery 230. M. Rhein wishes to thank M. Elbrächter and the late K. Bahrenfuss for analyzing the CFC samples on the Valdivia and Meteor cruises. O. Plähn processed the M39-2 dataset and K. Bulsiewicz analyzed and processed the Meteor M39-3 data. Contributions from the Scripps Institution of Oceanography were supported by the Ocean Sciences Section of the U.S. National Science Foundation. W. Smethies's work was supported by ONR Grant 0014-96-0612 and NSF Grant OCE98-11034. The German contributions from IFM Kiel and the University Bremen were funded by the Bundesministerium für Forschung und Technologie (BMBF) and by the Deutsche Forschungsgemeinschaft (DFG).

\section{REFERENCES}

Böning, C. W., F. O. Bryan, W. R. Holland, and R. Döscher, 1996: Deep-water formation and meridional overturning in a high resolution model of the North Atlantic. J. Phys. Oceanogr., 26, $1142-1164$.

Bullister, J. L., and R. F. Weiss, 1988: Determination of $\mathrm{CCl}_{3} \mathrm{~F}$ and $\mathrm{CCl}_{2} \mathrm{~F}_{2}$ in seawater and air. Deep-Sea Res., 35, 839-853.

Clarke, A., and J.-C. Gascard, 1983: The formation of Labrador Sea Water: Part I: Large scale processes. J. Phys. Oceanogr., 13, $1764-1778$.

Cunnold, D. M., P. J. Fraser, R. F. Weiss, R. G. Prinn, P. G. Simmonds, S. R. Miller, F. N. Alyea, and A. J. Crawford, 1994: Global trends and annual releases of $\mathrm{CCl}_{3} \mathrm{~F}$ and $\mathrm{CCl}_{2} \mathrm{~F}_{2}$ estimated from ALE/ GAGE and other measurements from July 1987 to June 1991. J. Geophys. Res., 99, 1107-1126.

Curry, R. G., M. S. McCartney, and T. M. Joyce, 1998: Oceanic transport of subpolar climate signals to mid-depth subtropical waters. Nature, 391, 575-577.

Davis, R. E., 1998: Preliminary results from directly measuring middepth circulation in the tropical and South Pacific. J. Geophys. Res., 103, 24 619-24 639.

Delworth, T. L., and R. J. Greatbatch, 2000: Multidecadal thermohaline circulation variability driven by atmospheric surface flux forcing. J. Climate, 13, 1481-1495.

-, S. Manabe, and R. J. Stauffer, 1993: Interdecadal variations of the thermohaline circulation in a coupled ocean-atmosphere model. J. Climate, 6, 1993-2010.

Dickson, R. R., J. Lazier, J. Meincke, P. Rhines, and J. Swift, 1996: Long term coordinated changes in the convective activity of the North Atlantic. Progress in Oceanography, Vol. 38, Pergamon, 241-295.

Fischer, J., and F. Schott, 2002: Labrador Sea Water tracked by profiling floats-From the boundary current into the open North Atlantic. J. Phys. Oceanogr, 32, 573-584.

Fleischmann, U., H. Hildebrandt, A. Putzka, and R. Bayer, 2002: Transport of Iceland Scotland Overflow Water from the Iceland Basin to the West European Basin. Deep-Sea Res., in press.

Harvey, J. G., and A. Theodorou, 1986: The circulation of Norwegian Sea overflow water in the eastern North Atlantic. Oceanol. Acta, 9, 393-402.

Hurrell, J. W., 1995: Decadal trends in the North Atlantic Oscillation: Regional temperatures and precipitation. Science, 269, 676-679.

Körtzinger, A., M. Rhein, and L. Mintrop, 1999: Anthropogenic $\mathrm{CO}_{2}$ and CFCs: Man made tracers in unison in the North Atlantic Ocean. Geophys. Res. Lett., 26, 2065-2068.
Lazier, J. R. N., 1988: Temperature and salinity changes in the deep Labrador Sea, 1962-1986. Deep-Sea Res., 35, 1247-1253.

Lilly, J. M., P. B. Rhines, M. Visbeck, R. Davies, J. Lazier, F. Schott, and D. Farmer, 1999: Observing deep convection in the Labrador Sea during winter 1994/95. J. Phys. Oceanogr., 29, 2065-2098.

Marsh, R., 2000: Recent variability of the North Atlantic thermohaline circulation inferred from surface heat and freshwater fluxes. J. Climate, 13, 3239-3260.

McCartney, M. S., 1992: Recirculating components to the deep boundary current of the northern North Atlantic. Progress in Oceanography, Vol. 29, Pergamon, 283-383.

- , and L. D. Talley, 1984: Warm-to-cold conversion in the northern North Atlantic Ocean. J. Phys. Oceanogr., 14, 922-935.

Molinari, R. L., R. A. Fine, W. D. Wilson, R. G. Curry, J. Abell, and M. S. McCartney, 1998: The arrival of recently formed Labrador Sea Water in the Deep Western Boundary Current at $26.5^{\circ} \mathrm{N}$ Geophys. Res. Lett., 25, 2249-2252.

Nurser, A. J. G., R. Marsh, and R. G. Williams, 1999: Diagnosing water mass formation from air-sea fluxes and surface mixing. J. Phys. Oceanogr., 29, 1468-1487.

Pickart, R. S., 1992: Water mass components of the North Atlantic deep western boundary current. Deep-Sea Res., 9, 1553-1572.

Price, J. F., and O'Neil-Baringer, 1994: Outflow and deepwater production by marginal seas. Progress in Oceanography, Vol. 33, 161-200.

Rhein, M., 1991: Ventilation rates of the Greenland and Norwegian Seas derived from distributions of the chlorofluoromethanes F11 and F12. Deep-Sea Res., 38, 485-503.

1995: Deep water formation in the Western Mediterranean. $J$. Geophys. Res., 100, 6943-6959.

1996: Convection in the Greenland Sea 1982-1993 J. Geophys. Res., 101, 18 183-18 192

Rossby, H. T., 1996: The North Atlantic Current and surrounding waters: At the crossroads. Rev. Geophys., 34, 463-481.

Schmitz, W. J., and M. S. McCartney, 1993: On the North Atlantic circulation. Rev. Geophys., 31, 29-49.

Smethie, W. M., and J. H. Swift, 1989: The tritium:krypton-85 age of Denmark Strait Overflow waters and Gibbs Fracture Zone Water just south of Denmark Strait. J. Geophys. Res., 94, 82658275 .

-, and R. A. Fine, 2001: Rates of North Atlantic Deep Water formation calculated from chlorofluorocarbon inventories. DeepSea Res., 48, 189-215.

- _ _ A. Putzka, and E. P. Jones, 2000: Tracing the flow of North Atlantic Deep Water using chlorofluorocarbons. J. Geophys. Res., 105, 14 297-14 323.

Speer, K., and E. Tziperman, 1992: Rates of water mass formation in the North Atlantic Ocean. J. Phys. Oceanogr., 22, 93-104.

Swift, J. H., 1984: The circulation of the Denmark Strait and IcelandScotland overflow waters in the North Atlantic. Deep-Sea Res., 31, 1339-1355

Sy, A., M. Rhein, J. R. N. Lazier, K. P. Koltermann, J. Meincke, A. Putzka, and M. Bersch, 1997: Surprisingly rapid spreading of newly formed intermediate waters across the North Atlantic Ocean. Nature, 386, 675-679.

Talley, L. D., and M. S. McCartney, 1982: Distribution and circulation of Labrador Sea Water. J. Phys. Oceanogr., 12, 1189-1205.

Walker, S. J., R. F. Weiss, and P. K. Salameh, 2000: Reconstructed histories of the annual mean atmospheric mole fractions of the halocarbons CFC-11, CFC-12, CFC-113 and carbon tetrachloride. J. Geophys. Res., 105, 14 265-14 296.

Wallace, D. W. R., and J. R. N. Lazier, 1988: Anthropogenic chlorofluoromethanes in newly formed Labrador Sea Water. Nature, 332, 61-63.

Wood, R. A., A. B. Keen, J. F. B. Mitchell, and J. M. Gregory, 1999: Changing spatial structure of the thermohaline circulation in response to atmospheric $\mathrm{CO}_{2}$ forcing in a climate model. Nature, 399, 572-575.

Worthington, L. V., 1976: On the North Atlantic Circulation. The John Hopkins Oceanography Studies, No. 6, The Johns Hopkins University Press, $110 \mathrm{pp}$. 